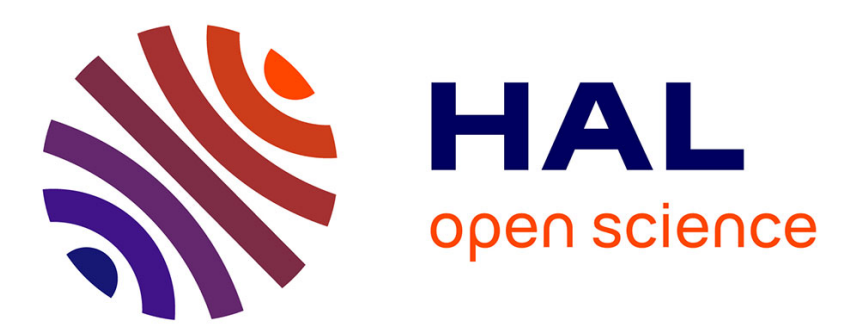

\title{
Formation of new bioactive organic nitrites and their identification with gas chromatography-mass spectrometry and liquid chromatography coupled to nitrite reduction.
}

Kristofer F. Nilsson, Michael Lundgren, Per Agvald, L. Christofer Adding, Dag Linnarsson, Lars E. Gustafsson

\section{To cite this version:}

Kristofer F. Nilsson, Michael Lundgren, Per Agvald, L. Christofer Adding, Dag Linnarsson, et al.. Formation of new bioactive organic nitrites and their identification with gas chromatography-mass spectrometry and liquid chromatography coupled to nitrite reduction.. Biochemical Pharmacology, 2011, 82 (3), pp.248. 10.1016/j.bcp.2011.04.005 . hal-00711297

\author{
HAL Id: hal-00711297 \\ https://hal.science/hal-00711297
}

Submitted on 23 Jun 2012

HAL is a multi-disciplinary open access archive for the deposit and dissemination of scientific research documents, whether they are published or not. The documents may come from teaching and research institutions in France or abroad, or from public or private research centers.
L'archive ouverte pluridisciplinaire HAL, est destinée au dépôt et à la diffusion de documents scientifiques de niveau recherche, publiés ou non, émanant des établissements d'enseignement et de recherche français ou étrangers, des laboratoires publics ou privés. 


\section{Accepted Manuscript}

Title: Formation of new bioactive organic nitrites and their identification with gas chromatography-mass spectrometry and liquid chromatography coupled to nitrite reduction.

Authors: Kristofer F. Nilsson, Michael Lundgren, Per Agvald, L. Christofer Adding, Dag Linnarsson, Lars E. Gustafsson

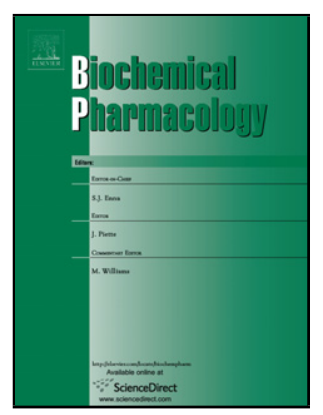

PII: S0006-2952(11)00244-9

DOI: doi:10.1016/j.bcp.2011.04.005

Reference: BCP 10877

To appear in: $\quad B C P$

Received date: $\quad 3-11-2010$

Revised date: $\quad$ 4-2-2011

Accepted date: $\quad$ 18-4-2011

Please cite this article as: Nilsson KF, Lundgren M, Agvald P, Adding LC, Linnarsson D, Gustafsson LE, Formation of new bioactive organic nitrites and their identification with gas chromatography-mass spectrometry and liquid chromatography coupled to nitrite reduction., Biochemical Pharmacology (2010), doi:10.1016/j.bcp.2011.04.005

This is a PDF file of an unedited manuscript that has been accepted for publication. As a service to our customers we are providing this early version of the manuscript. The manuscript will undergo copyediting, typesetting, and review of the resulting proof before it is published in its final form. Please note that during the production process errors may be discovered which could affect the content, and all legal disclaimers that apply to the journal pertain. 
Graphical Abstract

Development of novel lung selective organic nitrites with effects on exhaled NO, systemic blood pressure and pulmonary hypertension

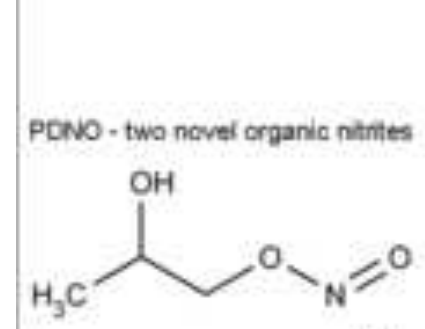

(1)

$\overbrace{\mathrm{CH}_{3}}^{\mathrm{O}} \mathrm{N}_{\mathrm{N}}=\mathrm{O}$
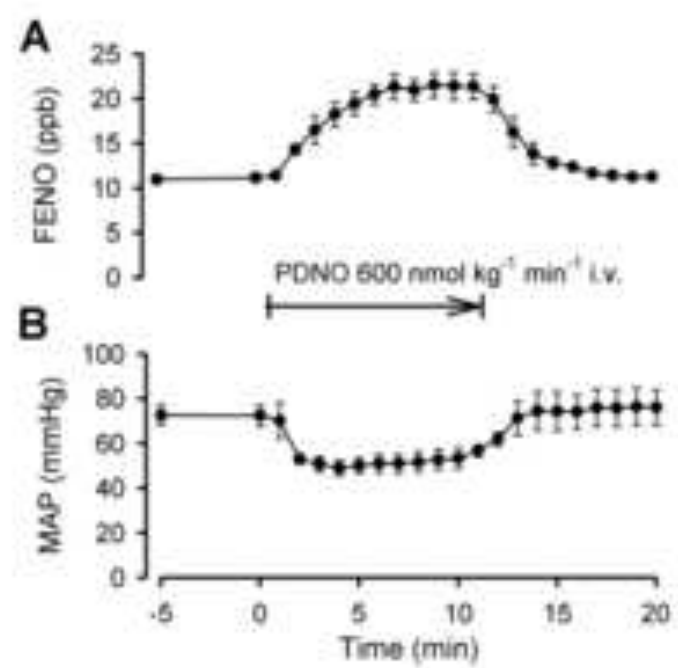

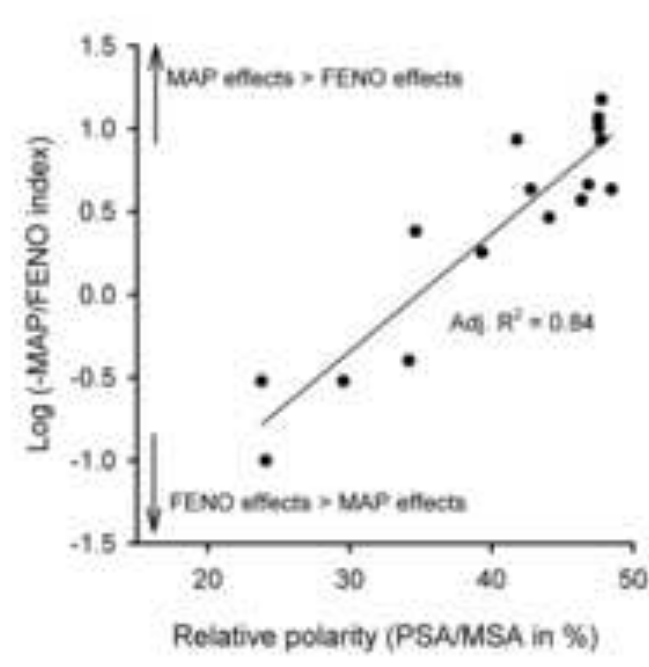

A

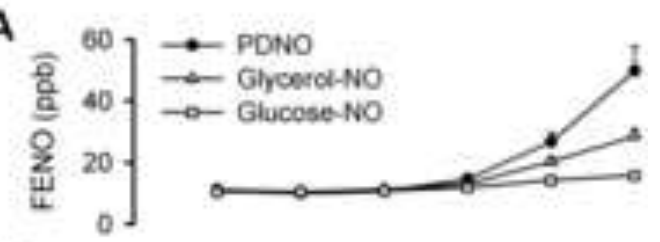

B

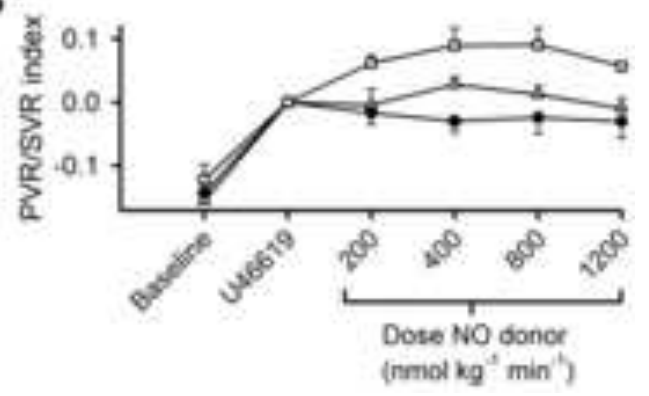


REVISED MANUSCRIPT

Formation of new bioactive organic nitrites and their

identification with gas chromatography-mass spectrometry and liquid chromatography coupled to nitrite reduction.

Kristofer F. Nilsson ${ }^{\mathrm{a}, ~}{ }^{\text {, }}$ Michael Lundgren ${ }^{\mathrm{b}}$, Per Agvald ${ }^{\mathrm{a}}$, L. Christofer Adding ${ }^{\mathrm{a}}$, Dag

Linnarsson $^{\mathrm{a}}$, Lars E. Gustafsson ${ }^{\mathrm{a}}$

${ }^{a}$ Department of Physiology and Pharmacology, Karolinska Institutet, SE-171 77 Stockholm, Sweden

${ }^{\mathrm{b}}$ Analyscentrum, Box 11538, SE-100 61 Stockholm, Sweden

* Correspondence:

Address: Kristofer F Nilsson, Department of Physiology and Pharmacology, von Eulers väg 8, SE-171 77 Stockholm, Sweden

Email: kristofer.nilsson@ki.se

Phone: +46852487192

Fax: +468327026

E-mails: ML: Michael.Lundgren@akzonobel.com; PA: per.agvald@sll.se; LCA:

christofer.adding@ki.se; DL: dag.linnarsson@ki.se; LEG: lars.gustafsson@ki.se 


\begin{abstract}
Nitric oxide (NO) donors, notably organic nitrates and nitrites are used therapeutically but tolerance develops rapidly, making the use of e.g. nitroglycerin difficult. NO donation in the pulmonary vascular bed might be useful in critically ill patients. Organic nitrites are not associated with tachyphylaxis but may induce methaemoglobinemia and systemic hypotension which might hamper their use. We hypothesised that new lung-selective NO donors can be identified by utilizing exhaled NO as measure for pulmonary NO donation and systemic arterial pressure to monitor hypotension and tolerance development. Solutions of alcohols and carbohydrates were reacted with NO gas and administered to ventilated rabbits for evaluation of in vivo NO donation. Chemical characterization was made by liquid chromatography with on-line nitrite reduction (LC-NO) and by gas chromatography-mass spectrometry (GC-MS). In vivo experiments showed that the hydroxyl-containing compounds treated with NO gas yielded potent NO donors, via nitrosylation to organic nitrites. Analyses in LC-NO showed that the reaction products were able to release NO in vitro. In GC-MS the reaction products were determined to be the organic nitrites, where some are new chemical entities. Non-polar donors preferentially increased exhaled NO with less effect on systemic blood pressure whereas more polar molecules had larger effects on systemic blood pressure and less on exhaled NO. We conclude that new organic nitrites suitable for intravenous administration are produced by reacting NO gas and certain hydroxyl-containing compounds in aqueous solutions. Selectivity of different organic nitrites towards the pulmonary and systemic circulation, respectively, may be determined by molecular polarity.
\end{abstract}


Key words: nitric oxide donors; nitrites; pulmonary circulation; hypertension, pulmonary;

chromatography, high pressure liquid 


\section{Introduction}

Nitric oxide donors are used to supply a patient with exogenous nitric oxide (NO) and can be used in conditions and diseases where increased NO is thought to be beneficial. There is a wide range of NO donors with different chemistry and biochemistry available for experimental use [1]. The list of conditions and diseases is extensive for where experimental studies have suggested beneficial effects, but only a few compounds are used in clinical practice [2]. Nitroglycerin and isosorbide mononitrate are used in acute and chronic anginal pain respectively and nitroglycerin may be used in the treatment for anal fissure [2].

Isosorbide dinitrate together with hydralazine is used for heart failure in African-Americans [2]. Inhaled amyl nitrite has been used in anginal pain and as an antidote in life-threatening cyanide intoxication [3]. Organic nitrates and organic nitrites are converted to NO in vivo which can be seen as increased exhaled NO and decreased systemic blood pressure $[4,5]$. A significant clinical problem with organic nitrates is the rapid tolerance development which can be demonstrated experimentally with decreased generation of NO to exhaled air $[6,7]$. Organic nitrites exhibit little or no tolerance [8], and recently ethyl nitrite has been suggested as an inhaled therapeutic [9]. However, the use of ethyl nitrite and other organic nitrites have been questioned due to significant methaemoglobin formation and other serious adverse effects $[10,11]$. Sodium nitroprusside is used in hypertensive crises but is associated with tolerance development and risk of cyanide intoxication and its use is sometimes therefore discouraged [12]. Inhaled NO is used in persistent pulmonary hypertension of the newborn [13] whereas use of inhaled NO in acute lung injury and acute respiratory distress syndrome is not recommended [14]. Other conditions where treatment with exogenous NO has been suggested from experimental studies include myocardial ischemia reperfusion $[15,16]$, splanchnic ischemia reperfusion and acute intestinal inflammation [17], stroke [18], 
pulmonary hypertension [19] and sepsis [20]. The reasons for the lack of development of new

NO donors that actually reach clinical practice are complex and may include side-effects in the form of systemic hypotension, headache, lack of specificity, tolerance development and toxicity [2]. Altogether there is a quest for new NO donors [2]. We believe that there is a specific need for intravenous NO donors with selectivity for the pulmonary circulation and that can be used, for example, in acute pulmonary embolism, where recent data indicate a protective role of endogenous NO [21]. We hypothesised that new lung-selective NO donors can be identified by utilizing exhaled NO as measure for pulmonary NO donation and systemic arterial pressure to monitor hypotension and tolerance development. We find that NO donors are formed, in a solution suitable for intravenous delivery, when deoxygenated aqueous solutions of alcohols and carbohydrates are reacted with NO gas and that these NO donors have different selectivity towards the pulmonary and systemic circulations.

\section{Material and Methods}

\subsection{Preparation of reaction products between compounds and nitric oxide gas.}

Aqueous solutions of alcohols and sugars and related compounds (please refer to Table 1 and supplementary Table A.1) were prepared and placed in gas tight cylinders (volume 20-150 ml) with taps in both ends and a sideway port with a septum plug (F-145, Alltech Biotechnology, Ireland) in the middle portion. The cylinders were filled to $75 \%$ with solution, allowing a gaseous head-space. The solutions were deoxygenated by means of helium bubbling for $10 \mathrm{~min}$ and purged with pure nitric oxide gas for $3 \mathrm{~min}$. Samples and infusion solutions were drawn via the septum plug. 


\subsection{The HPLC system}

The following reverse phase HPLC systems were used in all the analyses: $\mathrm{C}_{18}$ column (ReproSil-Pur $120 \mathrm{C}_{18}$-AQ, 4x150 mm, 5 m, Dr. Maisch HPLC GmbH, AmmerbuchEntringen, Germany or Nova-Pak C18, Radial-Pak 8x100 mm, 4 m, Waters Inc., Milford, MA, USA) or a CN column (Nova-Pak CN, 8x100 mm Radial-Pak, $4 \mu \mathrm{m}$, Waters Inc.), two pumps (ConstaMetric III; LDC/Milton Roy, Riviera Beach, FL, USA), an injector (9125; Rheodyne, Cotati, CA, USA) with an injector loop of $2.2 \mathrm{ml}$, a variable UV-absorbance detector measuring at $227 \mathrm{~nm}$ or $254 \mathrm{~nm}$ (SpectroMonitor III; LDC/Milton Roy), and a scanning UV absorbance detector (2140 Rapid Spectral Detector; LKB, Bromma, Sweden). The absorbance from the SpectroMonitor III detector was recorded and the pumps were controlled by commercial hardware and software (CSW32; DataApex, Prague, The Czech Republic) and the signal from the scanning detector was recorded by Wavescan software (LKB) run in DosBox (open source; www.dosbox.com). Samples and standards were injected at volumes from $2 \mu \mathrm{l}$ to $2 \mathrm{ml}$. The flow rate of the mobile phase was $0.5-1 \mathrm{ml} \mathrm{min}^{-1}$ depending on the size of the column and consisted of A) 5-10 mM ammonium formate in water followed by increasing proportions of B) methanol or acetonitrile. Isocratic elution or a linear gradient starting with $100 \% \mathrm{~A}$ and with an increase of $3 \% \mathrm{~min}^{-1}$ of $\mathrm{B}$ was used. The effluent from the HPLC system could then either be sampled or continuously be passed into a nitrite reduction system for online measurement of $\mathrm{NO} / \mathrm{NO}_{2}{ }^{-}$/organic nitrites (see section 2.3).

\subsection{Online measurement of $\mathrm{NO} / \mathrm{NO}_{2}^{-}$by chemiluminescence.}


Aliquots or effluent from the HPLC were intermittently respectively continuously injected in

a temperature-controlled reaction chamber (total volume $300 \mathrm{ml}$ ) containing $75 \mathrm{ml}$ of $1 \%$ $(\mathrm{w} / \mathrm{v})$ sodium iodide in hot $\left(89^{\circ} \mathrm{C}\right)$ acetic acid. Inorganic and organic nitrites are reduced to NO in this environment but not inorganic nitrate and organic nitrates [22]. The reaction solution was purged with $\mathrm{N}_{2}$-gas $\left(200 \mathrm{ml} \mathrm{min}^{-1}\right)$ to deoxygenate the solution and to carry NO gas to a chemiluminescence NO analyzer system. In the NO analyzer ozone was produced in an oxygen flow of $100 \mathrm{ml} \mathrm{min}^{-1}$ and made to react in a vacuum chamber with the NO in the incoming gas from the reducing chamber (sample flow rate $150-200 \mathrm{ml} \mathrm{min}^{-1}$ ). In the NO+ozone reaction, excited $\mathrm{NO}_{2}$ is generated which emits one photon per molecule. The photons are counted by a photomultiplier tube and are linearly proportional to the NO content in the incoming gas. The signal from the photomultiplier tube was collected by a computerized data acquisition system (MP100 system with AcqKnowledge software, BIOPAC Inc., Goleta, CA, USA). The system was intermittently calibrated with aliquots (10$500 \mu \mathrm{l}$ ) of known amounts of sodium nitrite either by direct injection or via the HPLC system (detection limits: 5 pmol and 10 pmol respectively). The sensitivity of the photomultiplier tube was adjusted in order to measure in the linear range. Quantification of NO content was made by comparing peak area measurements with the peak area of a known amount of standard. In experiments where the HPLC effluent was introduced into the reaction chamber, the volume in the reaction chamber increased slowly and intermittent withdrawal of liquid was necessary. In order to minimise the interference of different volumes in the chamber, calibration was always done before and after each analysis. These calibrations were very similar and the mean between the two sets was used in the calculation of quantity. The HPLC together with the online continuous nitrite reduction is henceforth referred to as LC-NO.

\subsection{Gas chromatography coupled to mass spectrometry}


Eluted peaks from the HPLC with the reaction mixture of propanol and NO gas were collected in gas tight syringes and extracted by an equal volume of toluene in a small sealed sample vial, shaken briefly, and quickly separated by centrifugation, if necessary. Fractions were injected at $1 \mu \mathrm{l}$ onto an Agilent DB-5MS gas chromatography column (0.25 mm i.d., 30 m length, $1 \mu \mathrm{m}$ phase thickness, Agilent Technologies, Inc., Santa Clara, CA, US) at an initial temperature of $40^{\circ} \mathrm{C}$, thereafter the column temperature was raised by $10^{\circ} \mathrm{C}$ per min until a temperature of 200 or $250^{\circ} \mathrm{C}$ was reached. Detection of eluted compounds was made by an Agilent 5973 Mass Selective Detector (quadrupole MS, Agilent Technologies, Inc.). The gas chromatograph was an Agilent 6890 Series GC system with a 7673 autosampler (Agilent Technologies, Inc.). Data were collected and analyzed with an Enhanced Chemstation G1701 BA computer program with a Wiley $7 \mathrm{n}$ library of mass spectra (Agilent Technologies, Inc.). Alternatively, $1 \mu \mathrm{l}$ of reaction mixture consisting of 25-100\% propanol and NO gas was injected directly in the gas chromatography column thus bypassing the extraction procedure and the autosampling system. Commercial propyl nitrite was diluted in toluene and injected in the same way for comparison. In addition, $0.5 \mu 1$ samples of $25-100 \%$ 1,2-propanediol treated with NO gas were injected in the gas chromatography-mass spectrometry (GC-MS) system, now equipped with an Agilent DB-1701 column $(0.25 \mathrm{~mm}$ i.d., $30 \mathrm{~m}$ length, $0.25 \mu \mathrm{m}$ phase thickness, Agilent Technologies, Inc.), in a total He flow of $30 \mathrm{ml} \mathrm{min}^{-1}$, split fraction 1:5. Temperature gradient was as above. Mass spectrometry was either performed in electron impact mode, or in chemical ionisation mode using a chemical ionisation interface supplied with a methane flow.

\subsection{Anaesthesia and surgical preparation}


The experiments were approved by the local animal ethics committee. Male white New Zealand rabbits (body weight: 2.0-3.5 kg, $\mathrm{n}=34$ ) were anaesthetized with sodium pentobarbital via an ear vein $\left(6 \mathrm{mg} \mathrm{ml}^{-1}\right.$ in saline, $\left.50-70 \mathrm{mg} \mathrm{kg}^{-1}\right)$. The animals were placed in the supine position and tracheotomised to allow mechanical ventilation (fraction of inspired oxygen $\left(\mathrm{FiO}_{2}\right)=0.21$ ), using a constant volume ventilator (model 683, Harvard Apparatus, South Natick, MA, USA). The ventilator was supplied with NO-free air using a charcoal filter $(110 \times 11 \mathrm{~cm})$. Respiratory rate $\left(40 \mathrm{~min}^{-1}\right)$ and tidal volumes were adjusted to keep end-tidal $\mathrm{CO}_{2}$ at $4.5-5.0 \%$. A heparinised catheter was inserted in the left common carotid artery for mean arterial blood pressure (MAP) and heart rate (HR) recordings (pressure transducer PX600P, Edwards Lifescience LLC, Irvine, CA, USA), and for arterial blood sampling. Another catheter was inserted in the right jugular vein for administration of drugs. In experiments where the NO donating capabilities of the NO solutions were tested the preparation was complete at this point and the animals were allowed a 30-60 min intervention free period. In experiments with pharmacologically induced pulmonary hypertension a mid thoracotomy was performed and a flow probe around the ascending aorta (T201 system, Transonic Systems Inc., Ithaca, NY, USA) measured cardiac output. A heparinised catheter was introduced via the left jugular vein and advanced to the pulmonary artery for measurement of pulmonary artery pressure. Another catheter was inserted through the left atrial wall for left atrial pressure measurements, and central venous pressure was measured via the catheter in the right jugular vein. Pulmonary vascular resistance (PVR), systemic vascular resistance (SVR) and PVR/SVR index were calculated with the common formulas. After the surgery, the animals were allowed a 30-60 min intervention-free period to reach stable circulatory conditions and exhaled NO values. A continuous infusion containing glucose $\left(26 \mathrm{~g} \mathrm{l}^{-1}\right)$, dextran 70 (Macrodex, $\left.28 \mathrm{~g}^{-1}\right)$ and $\mathrm{NaHCO}_{3}\left(6.6 \mathrm{~g} \mathrm{l}^{-1}\right)$ was administered. In experiments where the NO donating capabilities of the NO solutions were tested sodium 
pentobarbital $\left(4.2 \mathrm{~g} \mathrm{l}^{-1}\right)$ was added to the infusate which was given at a rate of $5 \mathrm{ml} \mathrm{kg}^{-1} \mathrm{~h}^{-1}$. In infusate and the infusion rate was $10 \mathrm{ml} \mathrm{kg}^{-1} \mathrm{~h}^{-1}$.

\subsection{NO measurements in exhaled breath}

The fraction of NO in mixed exhaled gas (FENO) was continuously measured by means of a chemiluminescence based system (NIOX, Aerocrine AB, Solna, Sweden) sampling at 100$140 \mathrm{ml} \mathrm{min}^{-1}$ through a Naphion sampling catheter at the end of a mixing chamber (size: 5 tidal volumes) connected to the ventilator exhaust. Calibration was performed using certified NO standard gas in nitrogen (AGA Specialgas, Lidingö, Sweden).

\subsection{Experimental protocol for in vivo experiments on NO donors}

Rabbits received the candidate NO donor solutions (described in section 2.1) intravenously (syringe pump CMA/100, Carnegie Medicin AB, Stockholm, Sweden) at pre-determined flow rates into a standardized carrier flow (864 Syringe Pump, Univentor LTD, Zejtun, Malta) via the right jugular vein catheter. Each rabbit received more than one of the NO donor solutions and was allowed ample intervention-free periods (at least $30 \mathrm{~min}$ ) between infusions to reach stable baseline conditions and to exclude cross-tolerance. Initial experiments included also trials with NO-saturated isotonic saline and a lipid emulsion purged with $\mathrm{NO}$ as means of administering NO parenterally. Arterial blood samples were intermittently drawn from the arterial catheter and analyzed for blood gases, acid-base status, methaemoglobin and total haemoglobin (ABL 520, Radiometer A/S, Copenhagen, Denmark). In some experiments the 
endogenous NO production was inhibited with $N^{G}$-nitro-L-arginine methyl ester (L-NAME,

$30 \mathrm{mg} \mathrm{kg}^{-1}$ ). In experiments with pulmonary circulatory measurements (see section 2.5 ) the thromboxane mimetic U46619 was administered intravenously to the animals in a continuous infusion (10-30 $\mu \mathrm{g} \mathrm{ml}^{-1}$ in saline, $\left.150-750 \mathrm{ng} \mathrm{kg}^{-1} \min ^{-1}\right)$ in order to induce a stable pulmonary hypertension (target: increase in PVR by approximately 150\%). Thereafter one of the NO donor solutions or nitroglycerin $\left(1 \mathrm{mg} \mathrm{ml}^{-1}\right)$ were administered in cumulatively increasing doses (200-1600 nmol kg-1 $\mathrm{min}^{-1}$, calculated for NO donating groups, $10 \mathrm{~min}$ for each dose) while monitoring haemodynamics and respiratory gases, including FENO as well as intermittent checks of blood gases. Several NO donors were investigated in each animal in random order with at least $30 \mathrm{~min}$ in between.

\subsection{Computation of physicochemical descriptors}

The calculator plugin modules of MarvinSketch (version 5.2.6, ChemAxon Kft, Budapest, Hungary), accessed through ChemIDplus at the US National Library of Medicine, were used to obtain calculated molecular descriptors of the NO donor molecules. These descriptors included octanol/water partition coefficient $(\log \mathrm{P})$, molecular size descriptors (molecular weight, MW; molecular surface area, MSA; molar refractivity, maximal and minimal projection radii and projection area, polarizability), molecular shape descriptors (the ratios between maximal and minimal projection radii and projection area respectively), polar and non-polar surface area (PSA and NSA respectively) from which a relative polar surface area of each donor molecule (PSA(\%)) was calculated by dividing PSA with MSA. These descriptors were then used as independent variables in multiple linear regression models using the $\log (-\mathrm{MAP} / \mathrm{FENO})$ as the dependent variable. 


\subsection{Chemicals}

Propyl nitrite was purchased from Karl Industries Inc. (Aurora, OH, USA) and propyl nitrate was from ChemService Inc. (West Chester, PA, USA). Ethyl nitrite, isobutyl nitrite, butyl nitrite, sodium nitrite, L-NAME, methanol, 1-propanol, 2-propanol, 1,2-propanediol, 1,3propanediol, isobutanol, butanol, 2-deoxyribose, 1-O-methyl-2-deoxyribose, ribose, 6deoxygalactose, galactose, glucose, fructose, sucrose, lactobionic acid, inulin, fucoidan, dextran (MW $162000 \mathrm{~g} \mathrm{~mol}^{-1}$ ), alanine, glycine, 3-amino-1,2-propanediol, 2-amino-1,3propanediol, glucosamine and lactate were purchased from Sigma-Aldrich (St. Louis, MO, USA). Ethanol was from Kemetyl (Stockholm, Sweden). Glycerol, sorbitol, mannitol, polyethylene glycol 400 and ammonium formate were from VWR International AB (Stockholm, Sweden). U46619 was from Cayman Chemicals (supplied by Larodan Fine Chemicals AB, Malmö, Sweden). Nitroglycerin was from Schwarz Pharma AG (Monheim, Germany). Heparin (Kabi Vitrum, Stockholm, Sweden), dextran 70 (Macrodex, Pharmalink, Spånga, Sweden), Intralipid (20\%, Fresenius Kabi, Uppsala, Sweden) and sodium pentobarbital (Apoteksbolaget) were purchased from Apoteksbolaget, Stockholm, Sweden. Pure NO and calibration gases were from AGA gas AB (Lidingö, Sweden).

\subsection{Statistics}

Descriptive data are presented as mean \pm standard error of the mean. Comparisons between groups were made by one way ANOVA and repeated comparisons within one group were made by repeated measures ANOVA or a paired t-test. Multiple linear regressions were made 
by using the best subsets function. Models including variables with non-significant variables

$(\mathrm{P}>0.05)$ or with severe multicollinearity (Variance Inflation Factor $>4)$ were excluded. Linear correlations were made by using Pearson Product Moment Correlation. All statistical analyses were made by means of SigmaStat (v. 3.10.0) and SigmaPlot (v. 9.01, Systat Software Inc., San Jose, CA, USA). $\mathrm{P}<0.05$ was considered as significant.

\section{Results}

\subsection{NO treated lipid emulsion and glycerol infused intravenously in vivo}

Initial experiments showed that bolus infusions intravenously $(0.5-2.5 \mathrm{ml})$ of a lipid emulsion (Intralipid) saturated with pure NO gas transiently increased FENO paralleled with a transient drop in MAP (data not shown). These responses could not be reproduced by only the native lipid emulsion (data not shown). In another experiment a rabbit with inhibited endogenous NO production (L-NAME $30 \mathrm{mg} \mathrm{kg}^{-1}$ ) first for $30 \mathrm{~min}$ intravenously received deoxygenated saline equilibrated with $\mathrm{NO}$ gas $\left(0.5 \mathrm{ml} \mathrm{kg}^{-1} \mathrm{~min}^{-1}\right)$ and after a recovery period of 3 hours a 30 min intravenous infusion of deoxygenated lipid emulsion $\left(0.5 \mathrm{ml} \mathrm{kg}^{-1} \mathrm{~min}^{-1}\right)$ equilibrated with NO. Saline with NO gas yielded a small increase in FENO and a very high methaemoglobin concentration whereas the lipid emulsion treated with NO gas gave a large increase in FENO whereas methaemoglobin was essentially not changed (Figure 1). MAP decreased with both infusions (data not shown). However the lipid emulsion turned yellow indicating oxidation. When studying the table of content of the lipid emulsion it was noted that it contained glycerol, and therefore deoxygenated NO-equilibrated glycerol dissolved in water (glycerolNO) was infused intravenously in a rabbit with inhibited NO production (L-NAME $30 \mathrm{mg} \mathrm{kg}$ 
$\left.{ }^{1}\right)$. This resulted in increased FENO and decreased MAP. Thereafter the glycerol-NO solution

5). FENO increased and MAP decreased dose-dependently (Figure 2a) during glycerol-NO infusions whereas neither saline treated with NO nor unreacted glycerol in the same doses had these effects (data not shown). Heart rate increased with $36 \pm 2$ beats $\min ^{-1}$ from $283 \pm 28$ beats $\min ^{-1}$ during infusion $\left(100 \mu \mathrm{kg}^{-1} \mathrm{~min}^{-1}\right)$ of glycerol-NO. When studying the pattern of FENO and MAP during the infusion, both these parameters reached a stable plateau, thus indicating absence of tolerance development (Figure 3). It was also found that there was a curvilinear relationship between the increments in FENO and the change in MAP (Figure 2b), a relationship that was linear when FENO increased by less than $20 \mathrm{ppb}$ (this analysis was continued in section 3.4). Methaemoglobin levels remained low (data not shown) and other parameters did not change. These experiments suggested that an NO donor solution was created when deoxygenated solutions of lipid emulsion or glycerol were treated with NO gas.

\subsection{Identification of other starting materials exhibiting NO donation when reacted with NO gas}

More than 20 different alcohols and carbohydrates (Table 1 and supplementary Table A.1) were dissolved in water, deoxygenated 10 min with helium, bubbled 3 min with pure NO gas, transferred to a syringe and administered intravenously $\left(100 \mu \mathrm{kg}^{-1} \mathrm{~min}^{-1}\right)$ to rabbits in order to test NO donating capabilities (see following text, Table 1 and supplementary Table A.1). The capacity of NO donation in vivo was determined positive if FENO increased and MAP decreased. 
NO-treated monohydric alcohols (1-propanol, 2-propanol), dihydric alcohols (1,2-propanediol,

1,3-propanediol), trihydric alcohols (glycerol) and polymers of alcohol (polyethylene glycol) donated NO to exhaled air and decreased MAP (Table 1 and supplementary Table A.1). NOtreated monosaccharides (glucose, galactose, fructose, and ribose), monosaccharide alcohols (sorbitol and mannitol) and certain modified monosaccharides (fucose, 2-deoxy-ribose, 1-Omethyl-ribose) all had NO donor capabilities. Also NO-treated disaccharides (sucrose, lactobionic acid) and carbohydrate polymers (inulin, dextran, fucoidan) increased FENO and lowered MAP. Similar with glycerol-NO, all these compounds exhibited a rapid onset and offset in effects without acute tolerance as illustrated by NO-treated 1,2-propanediol (Figure 3 and data not shown). A common feature for these compounds and groups are that they contain at least one hydroxyl group. Some compounds that were tested did not exhibit NO donating capacity in vivo despite NO equilibration: 2-Amino-1,3-propanediol, 3-Amino-1,2propanediol, lactic acid, alanine, glycine, and glucosamine (Table 1). This indicates that amine or carboxyl groups close to the hydroxyl-group in the substrate molecule prevent the formation of the NO donor compounds.

\subsection{Chemical characterization and identification of NO donors.}

\subsubsection{Identification of reaction products with liquid chromatography coupled to on-line nitrite reduction}

In order to further characterize and identify the NO donating compounds HPLC coupled to on-line nitrite reduction (LC-NO) was developed. Analyses of water saturated with NO gas and water with inorganic nitrite showed that the NO gas/inorganic nitrite appeared with the 
front of the chromatogram and at the corresponding elution time when the $\mathrm{NO} /$ nitrite

recording was synchronized by adjusting for the time delay between the two detection methods. This peak was denoted peak I. The same synchronized front peak was seen in the LC-NO of all the analysed NO solutions and was thus regarded as emanating from the NO gas/inorganic nitrite of these solutions. In addition, in all the solutions investigated with HPLC or LC-NO (Table 1) there appeared UV absorbing peaks with UV absorbance maxima near $225 \mathrm{~nm}$, and with faint but for organic nitrites characteristic vibrational spectral peaks in the range 330-370 $\mathrm{nm}$. No other such novel peaks were seen when deareated but non-NO treated organic starting materials were chromatographed. In the LC-NO it was found that all these chromatographic peaks were capable to generate NO in refluxing conditions (Figure 4-6, Table 1 and data not shown). None of the investigated parent substrate compounds yielded such $\mathrm{NO}$ chemiluminescence signals in the nitrite-reducing LC-NO analysis. Furthermore, the number of eluted organic nitrite-like peaks correlated with the number of nitrosylation sites in the form of hydroxyls in the parent compounds. Thus, 1,2-propanediol treated with NO gas (PDNO) exhibited 2 peaks (II and III in Figure 4) and glycerol-NO gave two peaks (II and III in Figure 5) the second of which was several times larger than the other, compatible with glycerol having two equivalent primary hydroxyls and one secondary. NO-treated glucose (glucose-NO) gave 4 organic nitrite-like peaks discernible in the UV recording and which despite considerable coelution, due to peak broadening in the transfer capillary, were still discernible as three peaks when reaching the NO/nitrite analysis (Figure 6). HPLC analysis of sucrose (60\% in water, w/v) reacted with $\mathrm{NO}$ gas yielded 8 peaks including the front peak (data not shown). LC-NO analyses of these solutions were also made in reversed phase with gradients of methanol and acetonitrile, however no additional peaks were seen (data not shown). 
Further experiments were performed to verify the formation of organic nitrites. When analyzing commercially available propyl nitrite in methanol gradient elution there was a perfect match between the elution time (27.4 min) and UV absorbance between peak II in propanol-NO and authentic propyl nitrite. Propyl nitrate analyzed in the same system had a retention time of 23.7 min (approximately $55 \%$ of methanol, detection limit: 0.5 nmoles) and a UV maximum of $205 \mathrm{~nm}$ with no other specific UV absorbances. A corresponding peak was not found in the analysis of propanol-NO and therefore the content of propyl nitrate, if any, in the propanol-NO must be less than $2.5 \%$ of the content of propyl nitrite. Further comparisons with some commercial organic nitrites in HPLC and LC-NO were completely compatible with formation of the corresponding nitrites in the NO gas treated hydroxyl precursor solutions (Table 1). In the experiments with authentic organic nitrites it was also found that the stability of the authentic organic nitrites was poor in water and was markedly increased by dissolving them in deoxygenated water or more preferable in deoxygenated NO gas-saturated solution (data not shown).

In the LC-NO experiments the content of NO donor compounds in the NO donor solutions could be estimated, by comparison with aliquots of inorganic nitrite. The content was determined to be $1-5 \mathrm{mM}$ when the concentration of the carrier solutions were $3.3 \mathrm{M}(1,2-$ propanediol, glycerol and glucose). If the formed compounds were considered reacted with one NO molecule the relation between reacted carrier molecules to unreacted carrier molecules would be approximately 1:1000. Detection of the organic nitrites by e.g. NMR against this background was thus considered nearly futile, and attempts at identification with LC-MS yielded no conclusive data (unpublished results). The 3 solutions which appeared having the highest content of organic nitrites were therefore chosen for GC-MS analysis.

\subsubsection{Identification of reaction products with gas chromatography-mass spectrometry}


For mass spectrometry the $\mathrm{C}_{18}$ HPLC fractions corresponding to the 27.4 min peak from gradient elution of propanol-NO were injected on the GC-MS system and several peaks eluted. At the front (1.5 min) the expected air gas peaks (nitrogen, oxygen and $\mathrm{CO}_{2}$ ) were observed, together with a NO peak. At 3 min a peak exhibiting mass spectral characteristics for propyl nitrite was identified by the mass detector. Propanol was eluted and identified at $3.5 \mathrm{~min}$ in the GC-MS system, followed by small amounts of benzene (breakdown product of toluene) at $5.5 \mathrm{~min}$, and then a large toluene peak at $8 \mathrm{~min}$ followed (data not shown). Direct on-column injection of commercial propyl nitrite confirmed the elution time ( $3 \mathrm{~min})$ and mass spectral characteristics of propyl nitrite. Direct on-column injection of propanol-NO, obtained from the gas-tight reaction vessel, gave similar results but with a very large peak of propanol followed by toluene (data not shown). A solution of PDNO was similarly analyzed, using manual injection on an Agilent DB-1701 column (Figures 7-9). Two peaks were identified in the gas chromatogram (retention times $5.29 \mathrm{~min}$ and $6.15 \mathrm{~min}$ respectively) in the PDNO sample that were not found when injecting only 1,2-propanediol (Figure 7). The mass spectrum of the first of these peaks showed fragments of 30, 45 and 60 which are suggested to arise from the cleavage of the mononitrite of 1,2-propandiol when the hydroxyl at position 1 is nitrosylated (2-hydroxy propyl nitrite, Figure 8). The mass spectrum of the second peak showed fragments of $30,31,59$ and 74 which are suggested to arise from cleavage of the mononitrite of 1,2-propandiol when the hydroxyl at position 2 is nitrosylated (2-hydroxy-1methylethyl nitrite, Figure 9). A major abundance of mass fragment 30, a common fragment for organic nitrites, was found in the 2 chromatographic peaks for compound 1 and 2 (data not shown). Mass spectrometry using chemical ionization demonstrated the M-1 and M+1 molecular ions in the mass spectra for both compound 1 and 2 (data not shown), as should be expected from the structures shown with the mass spectra (Figures 8-9). Attempts at 
analyzing glycerol-NO by the same method failed due to chromatographic interference from the large amounts of unreacted glycerol.

\subsection{Determination of important molecular properties for selectivity to the pulmonary and systemic circulation respectively.}

Infusions of organic nitrites of PDNO, glycerol-NO and glucose-NO were studied in several rabbits and at different doses. By using increases of FENO less than $20 \mathrm{ppb}$, significant linear correlations were found between the increases in FENO (delta ppb from baseline) and the changes in MAP (\% of baseline) (data not shown). Linear regressions (forced to start at 0 ) showed that the slopes of the lines were different: PDNO $-2.4 \pm 0.5$, glycerol-NO $-2.9 \pm 0.5$ and glucose-NO -8.6 \pm 0.9 . The slope was denoted MAP/FENO-index and was used as a measure of selectivity of NO donation in the pulmonary circulation versus systemic circulation. By dividing the change in MAP (\% of baseline) with the increase in FENO from baseline (delta ppb), this index was generated for all NO donor solutions (supplementary Table A.1). A MAP/FENO index close to zero denoted relatively larger effects on FENO, i.e. pulmonary circulation, and a MAP/FENO index away from zero indicated comparably larger effects on MAP, i.e. the systemic circulation. The MAP/FENO index (i.e. selectivity) differed significantly between the NO donor solutions and it was hypothesized that the selectivity depended on molecular properties of the NO donors. The calculated molecular descriptors are shown in supplementary Table A.2 and the correlations between them are shown in supplementary Table A.3. The MAP/FENO index was made positive and transformed to logarithms ( $=\log -\mathrm{FENO} / \mathrm{MAP}$ index $)$ as it was found that this process increased its usefulness in linear regression analyses, due to the nature of the index. In multiple linear 
regression, relative polarity of the NO donor molecule, i.e. polar surface area divided with molecular surface area, showed to be the best predictor of the MAP/FENO index, i.e. the more relative polarity of the NO donor molecule, the more effects on MAP compared to FENO and vice versa (Figure 10 and supplementary Table A.4). The second best fit showed that the more non-polar surface area and the higher $\log \mathrm{P}$ value of the NO donor molecules gave more effects on FENO compared with MAP and vice versa (supplementary Table A.4). The third best fit indicated that the less polar surface area and the more non-polar surface area of the NO donor molecule predicted more effects on FENO versus MAP (supplementary Table A.4). Taken together the results from multiple linear regressions revealed that the polarity of the NO donor molecules was important for the selectivity towards the pulmonary versus the systemic circulation. Another important notion was that the very non-polar organic nitrites (e.g. propyl nitrites) and therefore theoretically the most lung selective compounds produced significant methaemoglobinemia thus limiting their use as therapeutics.

\subsection{Reversal of pharmacologically induced pulmonary hypertension}

The effects of PDNO, glycerol-NO, glucose-NO and nitroglycerin on pharmacologically induced pulmonary hypertension (obtained by means of i.v. infusion of the throboxane $\mathrm{A}_{2}-$ mimetic U46619 in 8 rabbits) in vivo were investigated. Hemodynamic parameters and blood gases were normal and essentially similar in each group at baseline and during U46619 infusion. U46619 increased mean pulmonary arterial pressure (mPAP; $15 \pm 1$ to $23 \pm 1 \mathrm{mmHg}$ ), PVR (26 \pm 2 to $\left.62 \pm 4 \mathrm{mmHg} \operatorname{min~} \mathrm{l}^{-1}\right), \operatorname{SVR}\left(203 \pm 14\right.$ to $\left.244 \pm 16 \mathrm{mmHg}^{\mathrm{min}} \mathrm{l}^{-1}\right)$ and PVR/SVR $(0.13 \pm 0.1$ to $0.26 \pm 0.1)$ and slightly decreased FENO (10.7 \pm 0.5 to $10.4 \pm 0.4 \mathrm{ppb})$, cardiac output $\left(330 \pm 20\right.$ to $\left.280 \pm 10 \mathrm{ml} \mathrm{min}^{-1}\right)$ and arterial partial pressure of oxygen $\left(\mathrm{PaO}_{2}, 12.4 \pm 0.4\right.$ to 
$11.8 \pm 0.4 \mathrm{kPa}$ ). Other parameters did not change due to U46619 (data not shown), including

MAP (70 \pm 4 versus 74 $\pm 3 \mathrm{mmHg})$. PDNO (n=4, 200-1200 $\mathrm{mmol} \mathrm{kg}^{-1} \mathrm{~min}^{-1}$, Figure 11), glycerol-NO ( $\left.\mathrm{n}=4,200-1200 \mathrm{nmol} \mathrm{kg}{ }^{-1} \mathrm{~min}^{-1}\right)$, glucose-NO $\left(\mathrm{n}=4,200-1200 \mathrm{nmol} \mathrm{kg}^{-1} \mathrm{~min}^{-1}\right)$ and nitroglycerin $\left(\mathrm{n}=3,200-1600 \mathrm{nmol} \mathrm{kg}{ }^{-1} \mathrm{~min}^{-1}\right.$ calculated on NO donating groups) dosedependently reversed the effects of U46619 on mPAP, PVR, cardiac output and $\mathrm{PaO}_{2}$ (data not shown) to normal or almost normal at the highest doses. The order of efficacy differed and was $\mathrm{PDNO}>$ glycerol-NO>nitroglycerin>glucose-NO. All four NO donors also decreased MAP and SVR dose-dependently but on these parameters the efficacy order was the reverse i.e. glucose-NO > nitroglycerin $>$ glycerol-NO $>$ PDNO. Notably, in two out of four experiments the highest infusion rate of glucose-NO $\left(1200 \mathrm{nmol} \mathrm{kg}^{-1} \mathrm{~min}^{-1}\right)$ had to be terminated due to extreme systemic hypotension and signs of left heart failure, probably due to inadequate perfusion of the myocardium. All four NO donors also increased FENO dose-dependently (Figure 12a), but their efficacy differed, i.e. PDNO>glycerol-NO>nitroglycerin $>$ glucose-NO. Most importantly the four NO donors differently changed the PVR/SVR index, i.e. an index of selectivity towards the pulmonary and systemic circulations. PDNO decreased the PVR/SVR index (Figure 12b), thus indicating increased selectivity for the pulmonary circulation. Glucose-NO was the most potent in increasing the PVR/SVR index (Figure 12b), thus indicating increased selectivity for the systemic circulation. Glycerol-NO (Figure 12b) and nitroglycerin (data not shown) affected the PVR/SVR index similarly by increasing it slightly. PDNO very slightly increased the methemoglobin level (from $0.4 \pm 0.2$ to $0.85 \pm 0.1 \%$ ) at the end of the cumulative infusions, whereas the three other NO donors left the methemoglobin concentration unchanged. Taken together these experiments clearly showed that the four investigated NO donors differed in selectivity for the pulmonary and systemic circulations respectively, and that FENO is an adequate marker for this difference. 


\section{Discussion}

For more than a century, organic nitrites have been used as volatile NO donors for relieving anginal pain. Further use has been limited due to problems with administration, dosing and adverse effects.

The present study introduces a method for producing potent NO donor solutions, evidenced by increases in exhaled NO and decreases of systemic blood pressure and by the ability to deliver NO gas in a nitrite reduction system after HPLC. The NO donor molecules were identified to be organic nitrites where two of them for the first time are described and identified with GC-MS. The selectivity of the NO donation towards the pulmonary and systemic circulation was dependent on the relative polarities of the NO donor molecules. The NO donor solutions were also potent in reversing pharmacologically induced pulmonary hypertension.

The present study provides further evidence that the rabbit in vivo model [4, 5, 23], with measurements of exhaled NO and systemic blood pressure, is an excellent way to explore the action of NO donors. In the present work we used it as a bioassay system in order to find new NO donors. Previously the model has been used to study the acute tolerance development to organic nitrates and other NO donors [6]. In the present study, the response on exhaled NO and systemic blood pressure to the organic nitrites showed a plateau pattern over time, indicating no acute tolerance development. This is in contrary to the response to nitroglycerin where a peak and plateau pattern was observed and taken as an indication of acute tachyphylaxis [6]. The lack of acute tolerance of other organic nitrites has previously been shown both in vivo and in vitro [8], constitutes a very important pharmacological difference 
between organic nitrites and organic nitrates and may therefore encourage the use of organic nitrites instead of organic nitrates in clinical settings.

Furthermore, our present experimental data on exhaled NO and systemic blood pressure indicated that different organic nitrites had differential effects on exhaled NO and systemic blood pressure. Therefore we used a MAP/FENO index previously used [6] to describe these differential effects and the data were compared with calculated molecular descriptors of the NO donor molecules. By screening multiple linear regression models it was found that the best fits included measures of polarity of the $\mathrm{NO}$ donor molecules, i.e. that more polarity of the NO donor molecules affected systemic blood pressure more and that less polarity of the donor molecules affected exhaled NO more. This novel structure activity comparison approach for organic nitrites might be useful in the future in designing organic nitrites with wanted effects and selectivity as has been suggested for rational design of other classes of compounds [24] and as used to understand important substructures for organic nitrates [25]. The experiments with pharmacologically induced pulmonary hypertension indicate that certain organic nitrites will be more selective for the pulmonary circulation (e.g. organic nitrites of 1,2-propanediol and glycerol) compared to the systemic circulation (e.g. organic nitrites of glucose). However this observation needs to be confirmed and extended in a future study.

A study of the exact mechanisms behind the relationship between the selectivity for the pulmonary circulation and the polarity of the organic nitrite molecules have to be confined to a future study, but some considerations can be made. Relative polarity can be regarded as a measure of lipophilicity. Since several measures of compound lipophilicity correlate well with cell membrane passage [26], one potential mechanism could be that non-polar organic nitrites have increased permeability through cell membranes and therefore are cleared by the lungs and reach the systemic circulation in smaller amounts. This idea would also explain why the 
most non-polar organic nitrites produced methemoglobin, since a fast passage into the red

blood cells should be expected. Other properties which have been shown to differ between organic nitrites, and may affect their half-lives and relative lung selectivity, are differences in efficacy in methaemoglobin formation [28], rate of hydrolysis [29], rate of transnitrosylation [29] and rate of enzymatic bioactivation the lung [30]. A short half-life of organic nitrites seems to be a general property of this group of compounds, although the extent of it may differ between the different individual compounds. In a study of intravenous infusions of isobutyl nitrite in rats the half-life, systematic clearance and distribution volume of this organic nitrite were determined to 1.3 min with a monoexponential decline, clearance being 10 times larger than cardiac output and with a distribution volume of $5.81 \mathrm{~kg}^{-1}$ [31]. In the present study, the effect half-lives of the studied organic nitrites are very short (approximately 1.5-3.0 min), as can be seen by the off response for glycerol-NO and PDNO in Figure 3. The short half-lives of organic nitrites simplify the use of them in an intensive care setting, since intravenous infusion of them will be highly controllable and therefore safe and easy to manage.

The present work introduces a method for analyzing inorganic and organic nitrites in HPLC coupled to a nitrite reduction system. The nitrite reduction system alone has previously been used in our laboratory in for example studying NO release from guinea-pig colon [32] and from rabbit corpus cavernosum [33]. Sen et al. [34] used a partly similar system (HPLC coupled to nitrite reduction) to analyze inorganic nitrite in food, saliva and urine. One development in the present study compared to Sen et al. [34] is the use of gradient elution in the HPLC. The method offers both high sensitivity (at least 10 pmoles, by the chemiluminescence) and specificity (different retention times by HPLC). We used the method for identifying and quantifying formed organic nitrites when NO gas was reacted with alcohols and carbohydrates, especially the method was of great use for the organic nitrites that 
could not be identified with GC-MS or LC-MS. When using this method some caution must

be taken in that some other compounds will give a signal in the ozone reaction (e.g. ethers) and that the nitrite reduction system can reduce both inorganic nitrite and O-nitrosylated compounds, as well as N-nitrosylated and S-nitrosylated compounds [35].

By using GC-MS and LC-NO, the reaction product between propanol and NO gas was identified to be propyl nitrite, a previously known organic nitrite. By using the same methods the reaction products between $\mathrm{NO}$ gas and 1,2-propanediol were identified to be the mononitrites of 1,2-propanediol (2-hydroxy propyl nitrite and 2-hydroxy-1-methylethyl nitrite). Although we were not able to identify the reaction products with GC-MS or LC-MS of the other NO donor solutions it is most likely that these NO donor compounds also are the organic mononitrites of the carrier molecules. The evidences are: 1) They were produced with the same method that produced organic nitrites unequivocally identified by GC-MS; 2) They showed similar NO donor capabilities in vivo; 3) The number of reaction products was associated with the number of hydroxyl groups in the carrier molecule. 4) The UV absorbance maxima were around 219-234 $\mathrm{nm}$ for all the reaction products which is around the same UV absorbance as authentic organic nitrites have as shown in this study and previously [36], and they exhibited characteristic vibrational spectra; 5) They released NO in the nitrite reduction system similar to authentic organic nitrites. 6) The starting material for the reaction was known.

Most previously known organic nitrites and that are commercially available include mononitrites of monohydric alcohols. Furthermore it has been shown that peroxynitrite is capable of nitration (adding $\mathrm{NO}_{2}$ ) and nitrosation (adding $\mathrm{NO}$ ) of glycerol thus forming glycerol mononitrate and glycerol mononitrite [37]. Similar reactions between peroxynitrite and glucose, fructose and glyceraldehyde have been suggested. Although the reaction products were not identified they displayed biological activities similar to organic nitrites or 
organic nitrates [37, 38]. It has also been suggested that glucose scavenges NO, particularly in

hyperglycemia, and that treatment of glucose with acidified sodium nitrite led to monoaddition of NO to the glucose molecule [39].

The present study does not aim to elucidate the mechanism by which the organic nitrites were formed in the reaction with $\mathrm{NO}$ gas. There are several classical ways to generate organic nitrites which include reaction of alcohols with nitrous acid or other nitrosating agents such as nitrosyl chloride and nitrosonium salts [40, 41] or nitrosyl exchange between an alcohol and an alkyl nitrite [29]. The latter principle is interesting for the present study as that means that in a compound with several hydroxyl-groups there will be an equilibrium and thus a mixture between the mononitrites of that compound and therefore it will not be possible to produce one specific organic mononitrite from for example 1,2-propanediol [29]. Grossi and Strazzari [42] produced cycloalkyl nitrites from the reaction of $\mathrm{NO}$ gas with parent cycloalkyl alcohols in the presence of oxygen. They suggested that the reaction in this situation is not through the NO molecule itself but rather from nitrous anhydride $\left(\mathrm{N}_{2} \mathrm{O}_{3}\right)$ which is formed in the reaction between $\mathrm{NO}$ and molecular oxygen $\left(4 \mathrm{NO}+\mathrm{O}_{2} \rightarrow 2 \mathrm{~N}_{2} \mathrm{O}_{3}\right.$ ). From the present work we can not determine the exact mechanism for the formation of organic nitrites in our system, and it is difficult to exclude trace amounts of oxygen in the reaction chamber. Therefore the reaction may involve a direct action of $\mathrm{NO}$ on the hydroxyl groups of the carrier molecules or it may involve a nitrosating agent such as $\mathrm{N}_{2} \mathrm{O}_{3}$ (formed by the reaction of $\mathrm{NO}$ gas and trace amounts of oxygen) or it may be another, for us unknown, mechanism.

We conclude that new organic nitrites suitable for intravenous administration are produced by reacting $\mathrm{NO}$ gas and certain hydroxyl-containing compounds in aqueous solutions. In this work we have also developed a new method where liquid chromatography is coupled to nitrite reduction, which can be of great use, due to high sensitivity, in identifying possible endogenous organic nitrites in body fluids. Selectivity of different organic nitrites to the 
pulmonary and systemic circulation, respectively, is dependent on the relative polarity of the

specific organic nitrite. The nature of organic nitrite will also determine the tendency for methaemoglobin formation. Thus, by careful choice of NO donor molecule methaemoglobin formation may be avoided in therapeutically active doses. The present study shows that PDNO is relatively more selective to the lung compared with one clinically used NO donor, nitroglycerin, which should encourage future investigations on organic nitrites in disease models of pulmonary hypertension. We thus believe that the present study will stimulate further research in the field of organic nitrites as NO donors.

\section{Acknowledgements and role of funding sources}

This study was supported by the European Space Agency, the Swedish National Space Board, Fraenckel's Foundation for Medical Research, the Lars Hierta Foundation, the Swedish Science Council project 07919, the Swedish Heart-Lung Foundation and the Karolinska Institutet (MD/OD/PhD program grant). The funding sources solely provided financial support and were not involved in any part of the conduct of the research.

\section{Statement of conflicts of interest}

The authors (except ML) have filed patent applications on organic nitrites. LEG is a minority shareholder and member of the board of directors of Aerocrine $\mathrm{AB}$ (publ.) and is an inventor of patents concerning the use of exhaled nitric oxide. 


\section{References}

[1] Wang PG, Xian M, Tang X, Wu X, Wen Z, Cai T, et al. Nitric oxide donors: chemical activities and biological applications. Chem Rev 2002;102:1091-134.

[2] Miller MR, Megson IL. Recent developments in nitric oxide donor drugs. Br J Pharmacol 2007;151:305-21.

[3] Lavon O, Bentur Y. Does amyl nitrite have a role in the management of pre-hospital mass casualty cyanide poisoning? Clin Toxicol (Phila) 2010;48:477-84.

[4] Persson MG, Agvald P, Gustafsson LE. Detection of nitric oxide in exhaled air during administration of nitroglycerin in vivo. Br J Pharmacol 1994;111:825-8.

[5] Cederqvist B, Persson MG, Gustafsson LE. Direct demonstration of NO formation in vivo from organic nitrites and nitrates, and correlation to effects on blood pressure and to in vitro effects. Biochem Pharmacol 1994;47:1047-53.

[6] Agvald P, Adding LC, Gustafsson LE, Persson MG. Nitric oxide generation, tachyphylaxis and cross-tachyphylaxis from nitrovasodilators in vivo. Eur J Pharmacol 1999;385:137-45.

[7] Husain M, Adrie C, Ichinose F, Kavosi M, Zapol WM. Exhaled nitric oxide as a marker for organic nitrate tolerance. Circulation 1994;89:2498-502.

[8] Bauer JA, Nolan T, Fung HL. Vascular and hemodynamic differences between organic nitrates and nitrites. J Pharmacol Exp Ther 1997;280:326-31.

[9] Moya MP, Gow AJ, Califf RM, Goldberg RN, Stamler JS. Inhaled ethyl nitrite gas for persistent pulmonary hypertension of the newborn. Lancet 2002;360:141-3.

[10] Abman SH, Kinsella JP. Inhaled ethyl nitrite gas for persistent pulmonary hypertension in infants. Lancet 2002;360:2076-7. 
[11] Lavon O, Bentur Y. Does amyl nitrite have a role in the management of pre-hospital

[12] Varon J. Treatment of acute severe hypertension: current and newer agents. Drugs 2008;68:283-97.

[13] Clark RH, Kueser TJ, Walker MW, Southgate WM, Huckaby JL, Perez JA, et al. Low-dose nitric oxide therapy for persistent pulmonary hypertension of the newborn. Clinical Inhaled Nitric Oxide Research Group. N Engl J Med 2000;342:469-74.

[14] Afshari A, Brok J, Moller AM, Wetterslev J. Inhaled nitric oxide for acute respiratory distress syndrome (ARDS) and acute lung injury in children and adults. Cochrane Database Syst Rev 2010;7:CD002787.

[15] Schulz R, Kelm M, Heusch G. Nitric oxide in myocardial ischemia/reperfusion injury. Cardiovasc Res 2004;61:402-13.

[16] Bolli R. Cardioprotective function of inducible nitric oxide synthase and role of nitric oxide in myocardial ischemia and preconditioning: an overview of a decade of research. J Mol Cell Cardiol 2001;33:1897-918.

[17] Lefer AM, Lefer DJ. Nitric oxide. II. Nitric oxide protects in intestinal inflammation. Am J Physiol 1999;276:G572-5.

[18] Willmot MR, Bath PM. The potential of nitric oxide therapeutics in stroke. Expert Opin Investig Drugs 2003;12:455-70.

[19] Tilton RG, Brock TA, Dixon RA. Therapeutic potential of endothelin receptor antagonists and nitric oxide donors in pulmonary hypertension. Expert Opin Investig Drugs 2001;10:1291-308.

[20] Lamontagne F, Meade M, Ondiveeran HK, Lesur O, Robichaud AE. Nitric oxide donors in sepsis: a systematic review of clinical and in vivo preclinical data. Shock 2008;30:653-9. 
[21] Nilsson KF, Gustafsson LE, Adding LC, Linnarsson D, Agvald P. Increase in exhaled nitric oxide and protective role of the nitric oxide system in experimental pulmonary embolism. Br J Pharmacol 2007;150:494-501.

[22] Walters CL, Gillatt PN, Palmer RC, Smith PL. A rapid method for the determination of nitrate and nitrite by chemiluminescence. Food Addit Contam 1987;4:133-40.

[23] Adding LC, Agvald P, Andersson LI, Jonzon B, Hoogstraate J, Gustafsson LE. Direct gas measurements indicate that the novel cyclooxygenase inhibitor AZD3582 is an effective nitric oxide donor in vivo. Br J Pharmacol 2005;145:679-87.

[24] van de Waterbeemd H, Camenisch G, Folkers G, Chretien JR, Raevsky OA. Estimation of blood-brain barrier crossing of drugs using molecular size and shape, and H-bonding descriptors. J Drug Target 1998;6:151-65.

[25] Koenig A, Roegler C, Lange K, Daiber A, Glusa E, Lehmann J. NO donors. Part 16: investigations on structure-activity relationships of organic mononitrates reveal 2nitrooxyethylammoniumnitrate as a high potent vasodilator. Bioorg Med Chem Lett $2007 ; 17: 5881-5$.

[26] Kramer SD. Absorption prediction from physicochemical parameters. Pharm Sci Technolo Today 1999;2:373-80.

[27] Liu X, Miller MJ, Joshi MS, Sadowska-Krowicka H, Clark DA, Lancaster JR, Jr. Diffusion-limited reaction of free nitric oxide with erythrocytes. J Biol Chem 1998;273:18709-13.

[28] Doyle MP, Pickering RA, da Conceicao J. Structural effects in alkyl nitrite oxidation of human hemoglobin. J Biol Chem 1984;259:80-7.

[29] Doyle MP, Terpstra JW, Pickering RA, LePoire DM. Hydrolysis, Nitrosyl Exchange, and Synthesis of Alkyl Nitrites. J Org Chem 1983;48:3379-82. 
[30] Meyer DJ, Kramer H, Ketterer B. Human glutathione transferase catalysis of the formation of S-nitrosoglutathione from organic nitrites plus glutathione. FEBS Lett 1994;351:427-8.

[31] Kielbasa W, Fung HL. Pharmacokinetics of a model organic nitrite inhalant and its alcohol metabolite in rats. Drug Metab Dispos 2000;28:386-91.

[32] Iversen HH, Wiklund NP, Gustafsson LE. Nitric oxide-like activity in guinea pig colon as determined by effector responses, bioassay and chemiluminescence analysis. Acta Physiol Scand 1994;152:315-22.

[33] Hallen K, Gustafsson LE, Wiklund NP. Nerve-induced release of nitric oxide from the rabbit corpus cavernosum is modulated by cyclic guanosine $3^{\prime}, 5^{\prime}$-monophosphate. Neuroscience 2005;133:169-74.

[34] Sen NP, Baddoo PA, Seaman SW. Rapid and sensitive determination of nitrite in foods and biological materials by flow injection or high-performance liquid chromatography with chemiluminescence detection. J Chromatogr A 1994;673:77-84.

[35] Jobgen WS, Jobgen SC, Li H, Meininger CJ, Wu G. Analysis of nitrite and nitrate in biological samples using high-performance liquid chromatography. J Chromatogr B Analyt Technol Biomed Life Sci 2007;851:71-82.

[36] Ungnade HE, Smiley RA. Ultraviolet Absorption Spectra of Nitroparaffins, Alkyl Nitrates, and Alkyl Nitrites. J Org Chem 1956;21:993-6.

[37] White CR, Moellering D, Patel RP, Kirk M, Barnes S, Darley-Usmar VM. Formation of the NO donors glyceryl mononitrate and glyceryl mononitrite from the reaction of peroxynitrite with glycerol. Biochem J 1997;328 (Pt 2):517-24.

[38] Moro MA, Darley-Usmar VM, Lizasoain I, Su Y, Knowles RG, Radomski MW, et al. The formation of nitric oxide donors from peroxynitrite. Br J Pharmacol 1995;116:1999-2004. 
[39] Brodsky SV, Morrishow AM, Dharia N, Gross SS, Goligorsky MS. Glucose scavenging of nitric oxide. Am J Physiol Renal Physiol 2001;280:F480-6.

[40] Williams DLH. Nitrosation reactions and the chemistry of nitric oxide. Amsterdam: Elsevier, 2004.

[41] Noyes WA. n-butyl nitrite. Organic Syntheses, Coll 1943;2:108-9.

[42] Grossi L, Strazzari S. A New Synthesis of Alkyl Nitrites: The Reaction of Alkyl Alcohols with Nitric Oxide in Organic Solvents. J Org Chem 1999;64:8076-9. 


\section{Tables}

Table 1 Overview of the formation and the identification of organic nitrites when reacting deoxygenated aqueous solutions of parent compounds with NO gas.

\begin{tabular}{|c|c|c|c|c|}
\hline Parent compounds & $\begin{array}{l}\text { NO donation } \\
\text { in vivo }\end{array}$ & $\begin{array}{c}\text { UV absorbance } \\
\text { in HPLC }\end{array}$ & $\begin{array}{l}\text { NO release } \\
\text { in LC-NO }\end{array}$ & $\begin{array}{c}\text { Identified by } \\
\text { GC-MS }\end{array}$ \\
\hline 1-Propanol & + & $+*$ & $t^{\#}$ & + \\
\hline 1,2-Propanediol & + & + & + & + \\
\hline Glycerol & + & + & + & \\
\hline Glucose & + & + & & \\
\hline Ethanol & & $+*$ & & \\
\hline Isobutanol & + & $+*$ & & \\
\hline Butanol & & $+*$ & & \\
\hline Sucrose & + & + & & \\
\hline 2-Propanol & + & & & \\
\hline 1,3-Propanediol & + & & & \\
\hline 2-Deoxyribose & + & & & \\
\hline 1-O-Methyl-2-deoxyribose & + & & & \\
\hline Ribose & + & & & \\
\hline 6-Deoxygalactose & + & & & \\
\hline Galactose & + & & & \\
\hline Fructose & + & & & \\
\hline Sorbitol & + & & & \\
\hline Mannitol & + & & & \\
\hline Lactobionic acid & + & & & \\
\hline Polyethylene glycol & + & & & \\
\hline Inulin & + & & & \\
\hline Dextran & + & & & \\
\hline Fucoidan & + & & & \\
\hline 2-Amino-1,3-propanediol & - & & & \\
\hline 3-Amino-1,2-propanediol & - & & & \\
\hline Lactic acid & - & & & \\
\hline Alanine & - & & & \\
\hline Glycine & - & & & \\
\hline Glucosamine & - & & & \\
\hline
\end{tabular}

The capacity of NO donation in vivo was determined positive if both exhaled NO increased and systemic blood pressure decreased (+). - denotes no NO donation capacity in vivo. UV absorbance in HPLC was denoted (+) if treatment with NO gas of parent compounds resulted in new chromatographic peaks exhibiting characteristic absorbance around $225 \mathrm{~nm}$ and vibrational absorbance in the range 330-370 nm [36]. *denotes that the new chromatographic peaks in HPLC had the same retention time and UV characteristics in HPLC as the corresponding authentic and commercially available organic nitrite. NO release in HPLC coupled to online nitrite reduction (LC-NO) was indicated $(+)$ if new chromatographic peaks also were confirmed to release NO in the nitrite reduction system. " indicates that authentic organic nitrite of the parent compound also released NO at identical retention time in the LCNO. Some of the formed compounds $(+)$ were identified with gas chromatography-mass spectrometry (GC-MS). Non-filled spaces in the table indicate that the corresponding analysis was not performed for that compound in that system. Absence of markers ${ }^{\#}$ and * means that commercial reference compounds were not available. 


\section{Figure captions}

Figure 1. Ventilated and anesthetized rabbit. Exhaled NO (FENO, panel A) and methaemoglobinemia (Met $\mathrm{Hb}$, panel B) during infusion $\left(0.5 \mathrm{ml} \mathrm{kg}^{-1} \mathrm{~min}^{-1}\right)$ of first $\mathrm{NO}$ gas dissolved in saline and then NO gas dissolved in lipid emulsion, as indicated by horizontal bars. Endogenous NO production was inhibited (L-NAME $30 \mathrm{mg} \mathrm{kg}^{-1}$ ) by an initial infusion at time $20 \mathrm{~min}$, also indicated by a horizontal bar. 
Figure 2. Ventilated anaesthetized rabbits $(n=4-5)$. Dose-response curves (panel A) of exhaled NO (FENO) and mean systemic arterial pressure (MAP) at several infusion rates of glycerol-NO (25\% glycerol in saline, v/v, treated with NO gas and identified by LC-NO to contain glyceryl nitrites). Panel B shows the correlation between the increase in FENO and change in MAP (\% of control). The fitted non-linear curve has the format of $y=y_{0}+a e^{-b x}$, where $y$ is change in MAP (\% of control), $\mathrm{x}$ is increase in FENO and $\mathrm{y}_{0}$, $\mathrm{a}$ and $\mathrm{b}$ are constants. Note that for infusions that increased FENO with less than $20 \mathrm{ppb}$, the relationship is linear between increase in FENO and decrease in MAP. 
Figure 3. Ventilated and anesthetized rabbits $(n=3-5)$. Exhaled NO (FENO, panels A and B),

mean arterial blood pressure (MAP, panels C and D) and heart rate (HR, panels E and F) during an intravenous infusion for 10 min of glycerol-NO (panels A, C, E; 25\% glycerol in saline, v/v, treated with NO gas and identified by LC-NO to contain glyceryl nitrites; $30 \mathrm{ul} \mathrm{kg}^{-}$ ${ }^{1} \mathrm{~min}^{-1}$ ) or PDNO (panels B, D, F; $25 \%$ 1,2-propanediol in saline, v/v, treated with NO gas and identified by GC-MS and LC-NO to contain the 1,2-propanediol nitrites; the dose was quantified to $\left.600 \mathrm{nmol} \mathrm{kg}^{-1} \mathrm{~min}^{-1}\right)$. 
Figure 4. LC-NO, i.e. HPLC (panel A) and reflux NO/nitrites analysis (panel B) for

identification of organic nitrites. Chromatogram obtained at $227 \mathrm{~nm}$ (panel A) and nitrite content (panel B) of $2.5 \mu \mathrm{L}$ of NO-treated 1,2-propanediol solution ( $25 \%$ in saline, v/v), injected at time 0 . Isocratic elution with $10 \mathrm{mM}$ ammonium formate on a $\mathrm{C}_{18}$ column (ReproSil-Pur $120 \mathrm{C}_{18}$-AQ, 150x4 mm, $5 \mu \mathrm{m}$ ). The three major peaks are marked I, II and III. Peak I corresponded to the retention time of NO/inorganic nitrite. Peak II and III had major UV absorbance maxima at 225 and $226 \mathrm{~nm}$ respectively and also exhibited weak but detectable vibrational spectra in the region $330-370 \mathrm{~nm}$. 
Figure 5. LC-NO, i.e. HPLC (panel A) and reflux NO/nitrites analysis (panel B) for

identification of organic nitrites. Chromatogram obtained at $227 \mathrm{~nm}$ (panel A) and nitrite content (panel B) of $2.5 \mu \mathrm{L}$ of NO-treated glycerol solution ( $25 \%$ in saline, $\mathrm{v} / \mathrm{v}$ ), injected at time 0. Isocratic elution with $10 \mathrm{mM}$ ammonium formate on a $\mathrm{C}_{18}$ column (ReproSil-Pur 120 $\mathrm{C}_{18}$-AQ, 150x4 mm, $\left.5 \mu \mathrm{m}\right)$. The three major peaks are marked I, II and III. Peak I corresponded to the retention time of NO/inorganic nitrite. Peak II and III had major UV absorbance maxima at $226 \mathrm{~nm}$ and also exhibited weak but detectable vibrational spectra in the region $330-370 \mathrm{~nm}$. 
Figure 6. LC-NO, i.e. HPLC (panel A) and reflux NO/nitrites analysis (panel B) for

identification of organic nitrites. Chromatogram obtained at $227 \mathrm{~nm}$ (panel A) and nitrite content (panel B) of $2.5 \mu \mathrm{L}$ of NO-treated glucose solution (60\% in saline, w/v), injected at time 0. Isocratic elution with $10 \mathrm{mM}$ ammonium formate on $\mathrm{C}_{18}$ column (ReproSil-Pur 120 $\mathrm{C}_{18}$-AQ, $\left.150 \mathrm{x} 4 \mathrm{~mm}, 5 \mu \mathrm{m}\right)$. The five major peaks are marked I-V. Peak I corresponded to the retention time of NO/inorganic nitrite. Peak II-V had major UV absorbance maxima at 226, 223, 234 and $224 \mathrm{~nm}$ respectively and also exhibited weak but detectable vibrational spectra in the region $330-370 \mathrm{~nm}$. 
Figure 7. Gas chromatography with mass detection (Agilent DB-1701 column and electron impact ionisation) after split fraction (1:5) injection at time $=0$ of $0.5 \mu 1$ de-aerated approximately $100 \%$ 1,2-propanediol treated with NO gas. Shown is a total ion chromatogram for the $\mathrm{m} / \mathrm{z}$ range 20-320. Peaks denoted 1 and 2 were further characterized with mass spectra in Figures 8-9. The peak denoted 1,2-propanediol was identical with the corresponding entry in the Wiley mass spectral library, whereas spectra for peak 1 and 2 were not found in the Wiley library or elsewhere. 
Figure 8. Electron impact ionisation spectrum of peak 1 from a similar chromatography as in

1

Figure 7, supporting the postulated structure of one of the two 1,2-propanediol nitrites (2hydroxy propyl nitrite) corresponding to the first of the two peaks in Figure 7. 
Figure 9. Electron impact ionisation spectrum of peak 2 from a similar chromatography as in

1

Figure 7, supporting the postulated structure of one of the two 1,2-propanediol nitrites (2hydroxy-1-methylethyl nitrite) corresponding to the second of the two peaks in Figure 7. 
Figure 10. Anesthetized and ventilated rabbits subjected to intravenous infusions of different

organic nitrite NO donor solutions. The MAP/FENO indices were calculated from experiments with intravenous infusions of NO donor solutions by dividing the change in MAP (\% of baseline) with increase in FENO (delta ppb compared with baseline, supplementary Table A.1). Each point represents one NO donor (Table 1 and supplementary Table A.1). Shown is also the best linear regression found (expression 1 in supplementary Table A.4) by exploring the dependent variable Log (-MAP/FENO index) against the independent variable relative polarity (PSA/MSA in \%, calculated as polar surface area divided with molecular surface area) for the different NO donors (Refer to supplementary Table A.2 for the list of compounds included) showing that relative polarity is a strong predictor for MAP versus FENO effects. 
Figure 11. Ventilated and anesthetized rabbit. The effects of intermittent infusions of NOtreated 1,2-propanediol (PDNO, doses of 130 and 450 nmoles $\mathrm{kg}^{-1} \mathrm{~min}^{-1}$ respectively) on successively increased U46619-induced pulmonary hypertension. The stippled vertical fields indicate treatment with PDNO. Measured parameters were mean pulmonary artery pressure (mPAP, panel A), mean left atrial pressure (LAP, panel B), pulmonary vascular resistance (PVR, panel C), mean systemic arterial blood pressure (MAP, panel D), exhaled NO (FENO, panel E), cardiac output (CO, panel F). 
Figure 12. Ventilated and anesthetized rabbits $(n=4)$. The effects of NO-treated 1,2-

propanediol (PDNO), NO-treated glycerol (Glycerol-NO) and NO-treated glucose (GlucoseNO) in doses of 200, 400, 800 and 1200 nmoles $\mathrm{kg}^{-1} \mathrm{~min}^{-1}$ administered intravenously on U46619-induced pulmonary hypertension. Measured parameters were the concentration of NO in mixed exhaled gas (FENO, panel A) and pulmonary vascular resistance divided with systemic vascular resistance (PVR/SVR, normalised to the PVR/SVR index during U46619 infusion). The effects of nitroglycerin (not shown in the Figure for reasons of clarity) on FENO and PVR/SVR index were similar to the effects of glucose-NO and glycerol-NO respectively. $\uparrow$ indicates that $\mathrm{n}=2$ for glucose-NO at 1200 nmoles $\mathrm{kg}^{-1} \mathrm{~min}^{-1}$ due to severe systemic hypotension. 


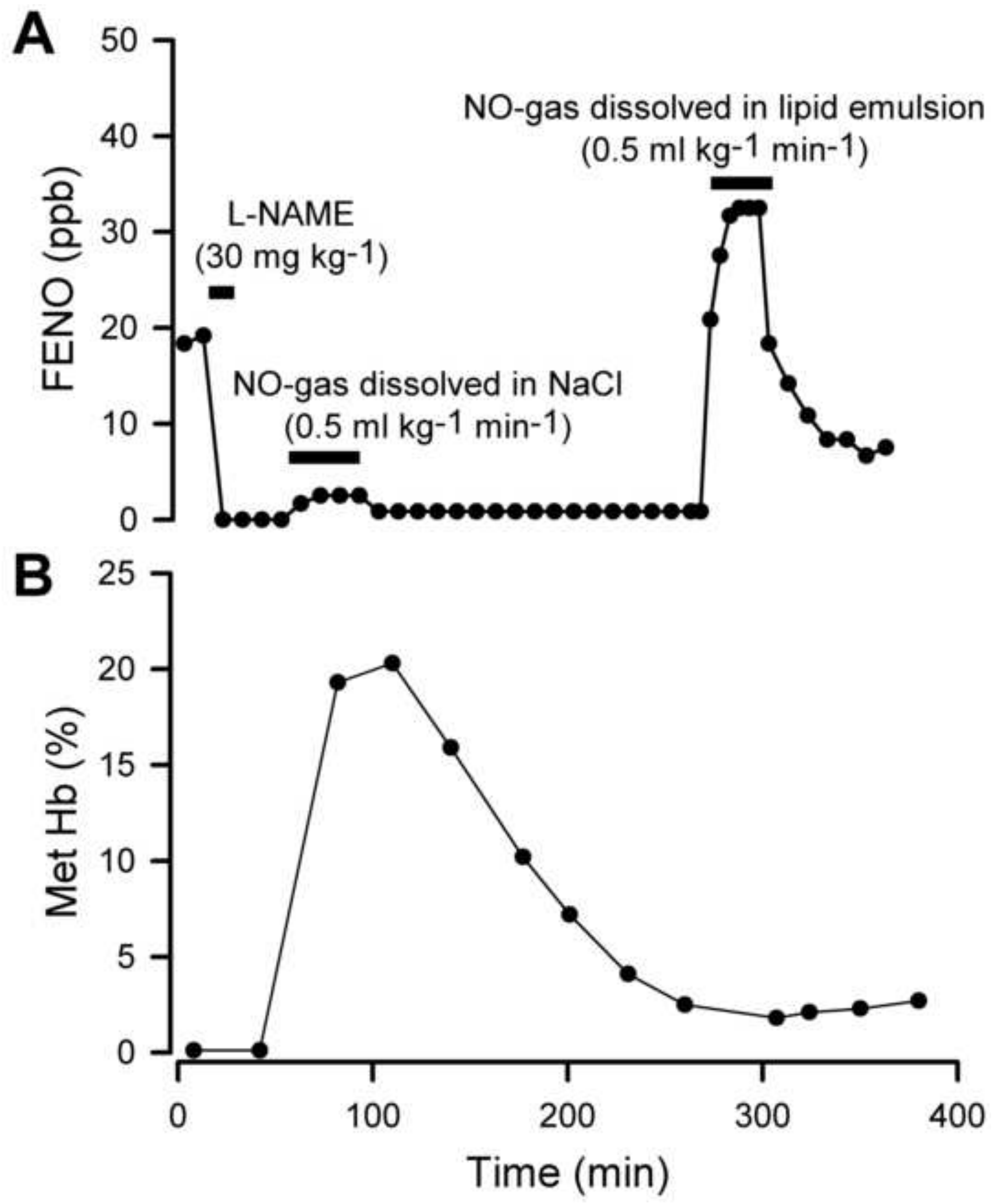



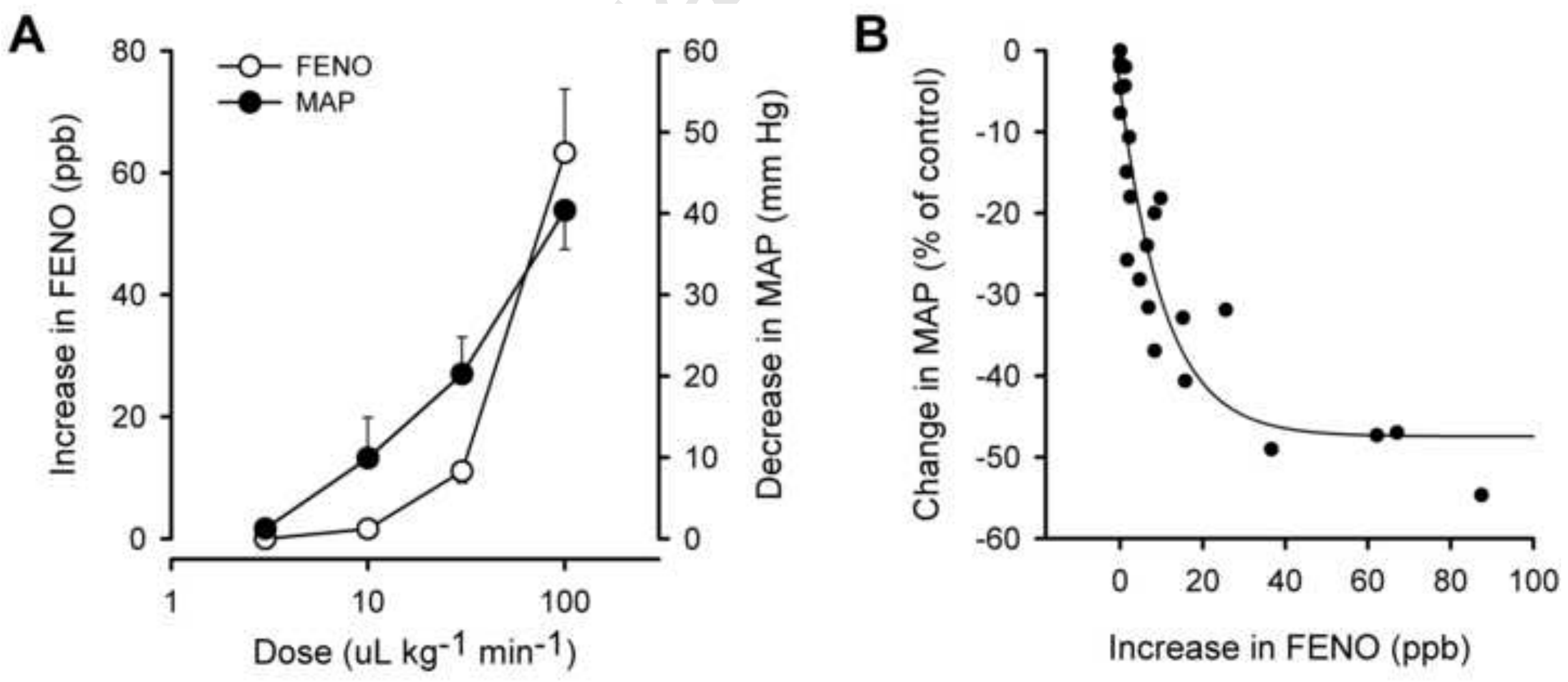
A

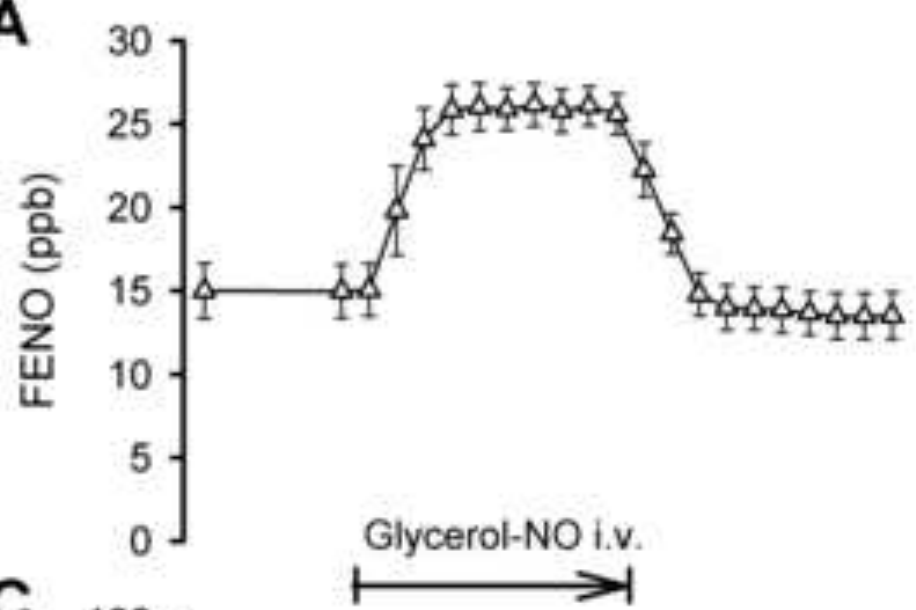

C $100 \mathrm{\longrightarrow}$

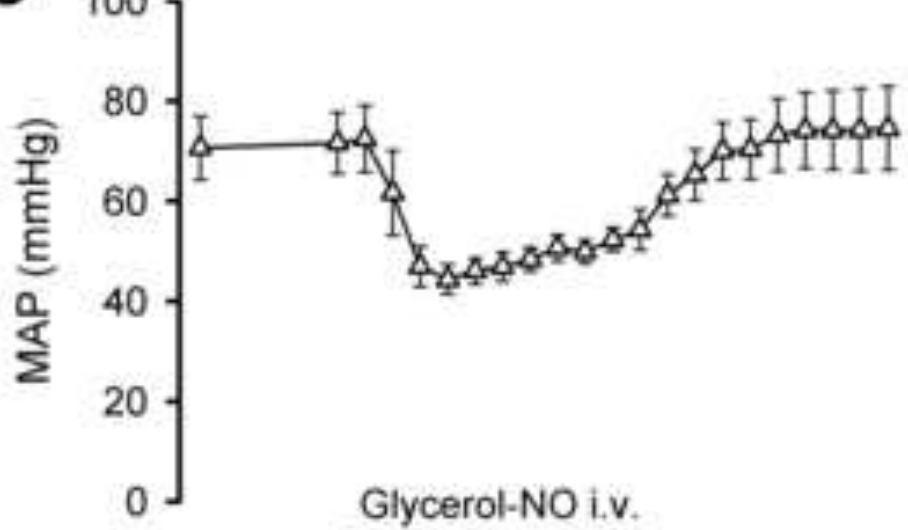

E

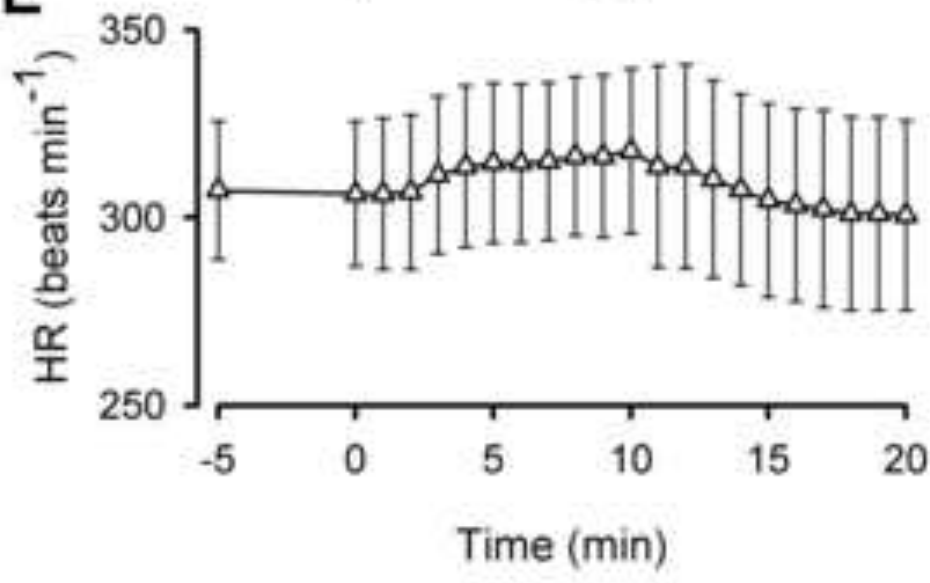

B

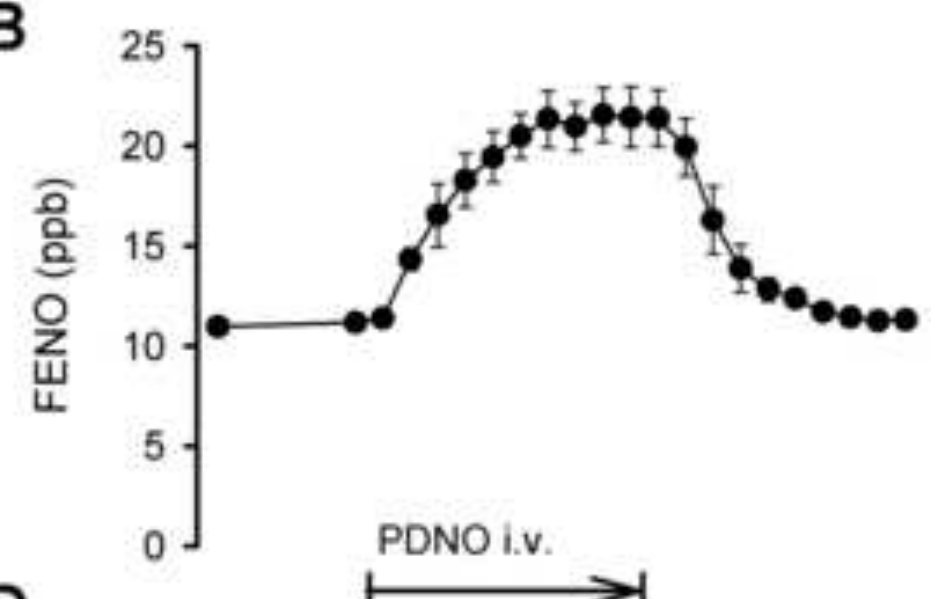

D $100 \mathrm{\longmapsto}$

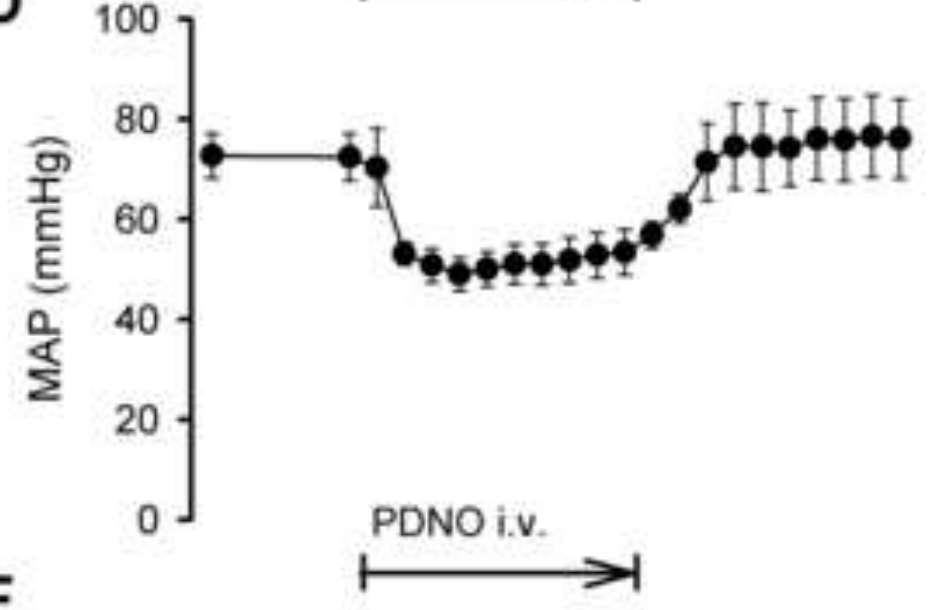

F

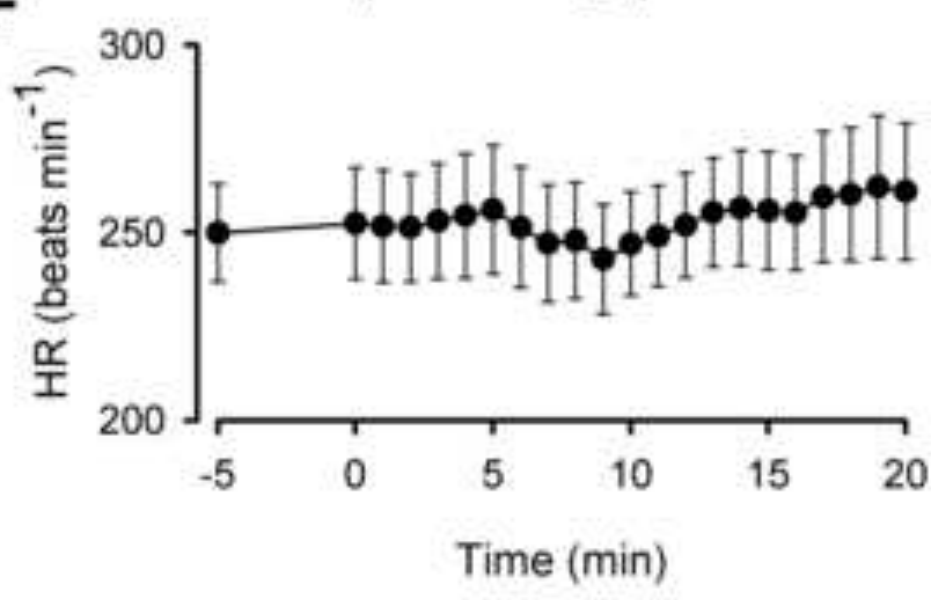




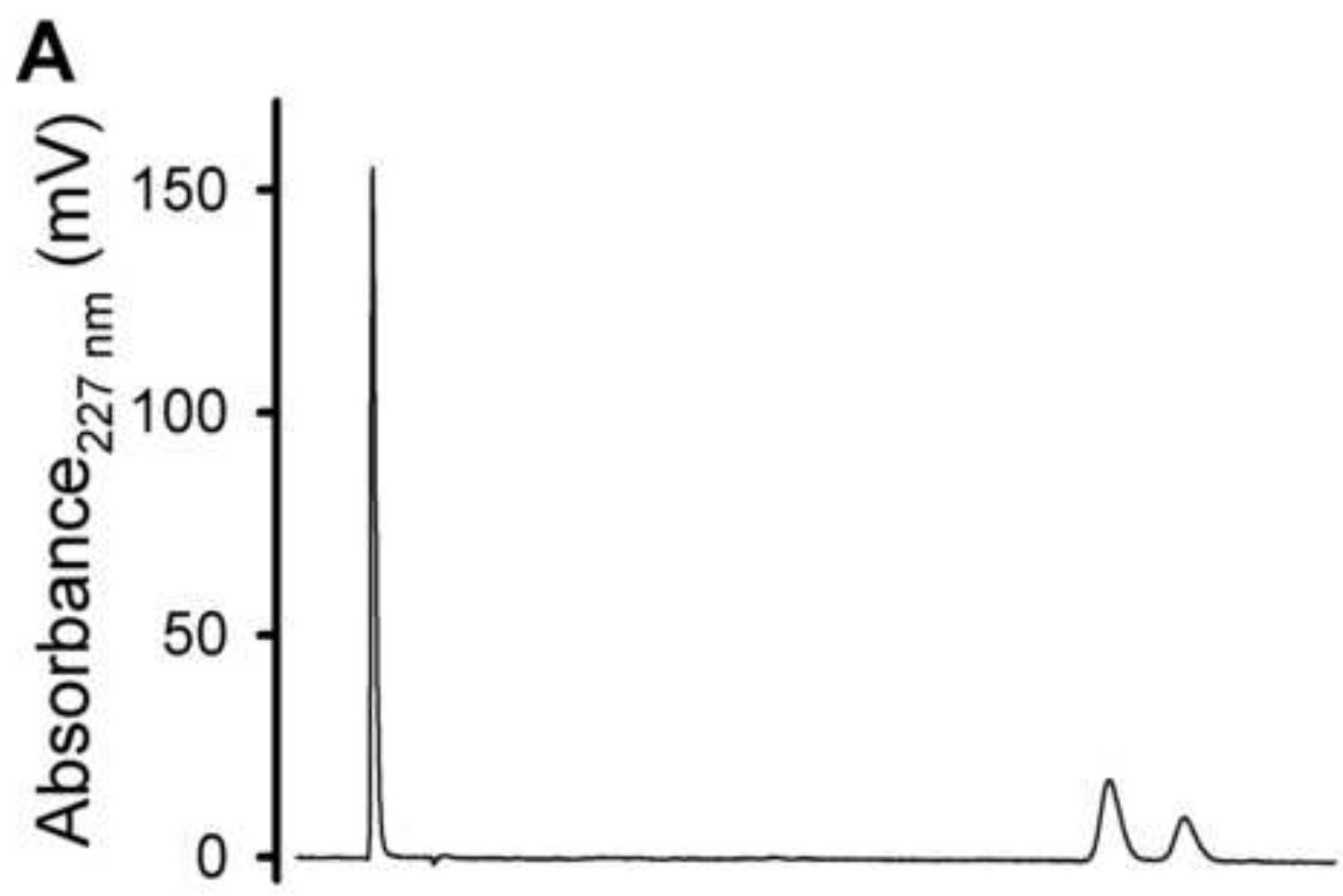

B

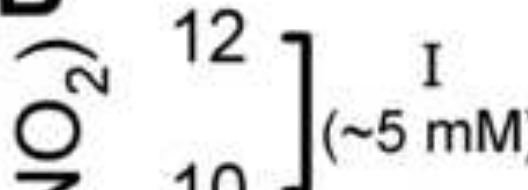

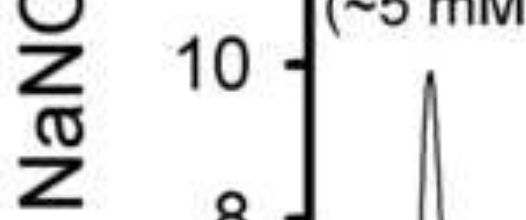

을

ํㅗㄴ

8
6
4
2
0

0

10

20

30

Time (min) 


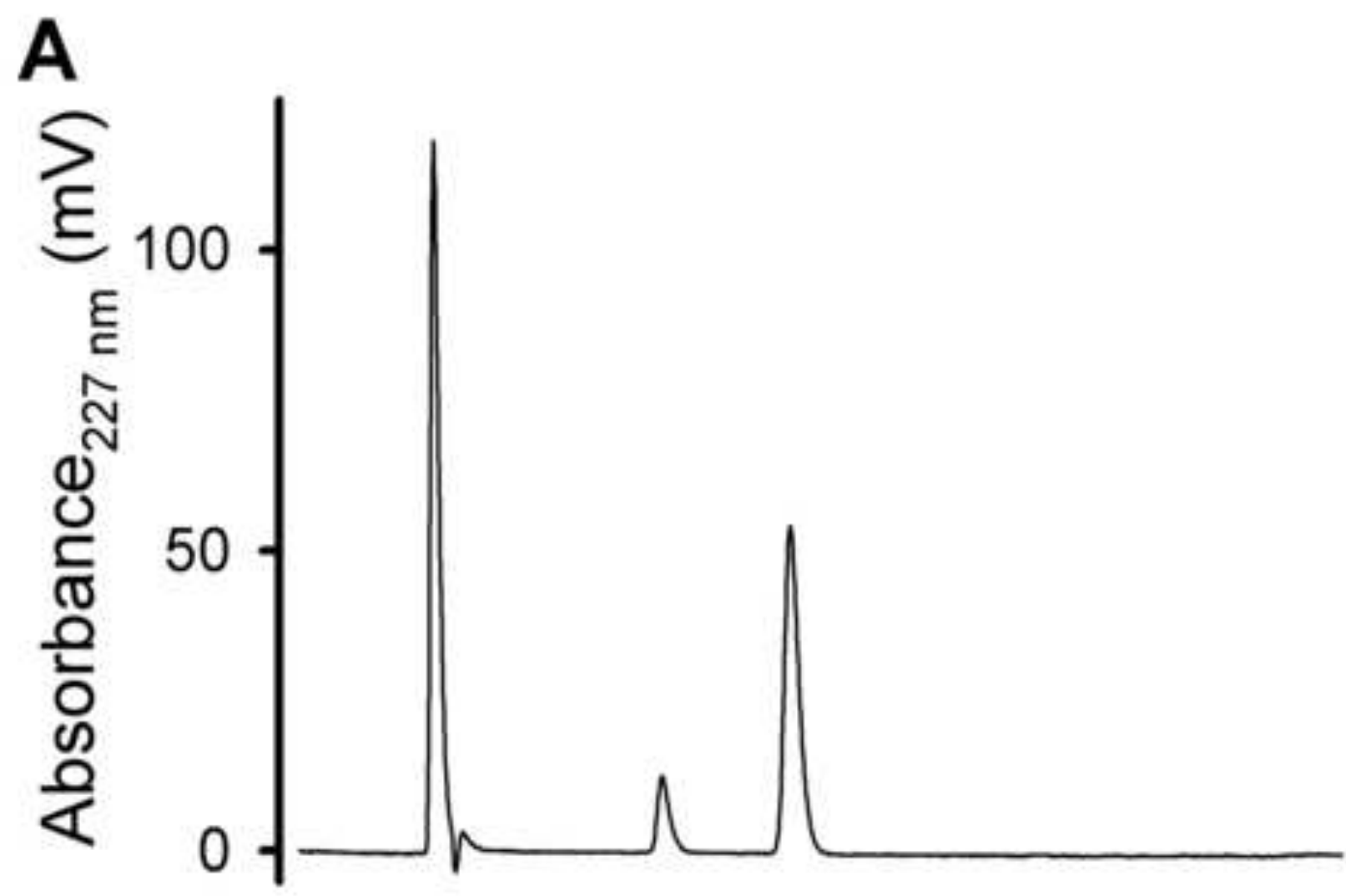

B

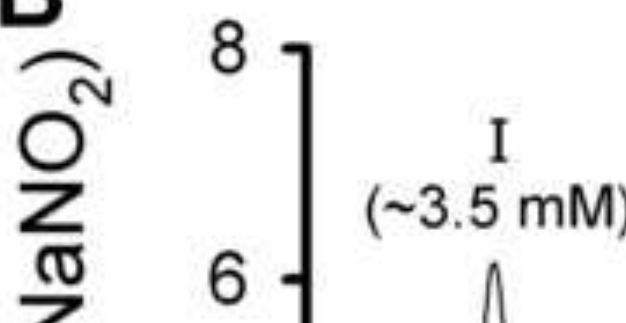

Z $6-1$

으 ( 2.9 mM)

气

$\frac{\text { D. }}{\text { 乙. }}$

4

2

1

II

$(\sim 0.5 \mathrm{mM})$

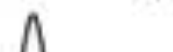

0

5

10

15

20

Time (min) 


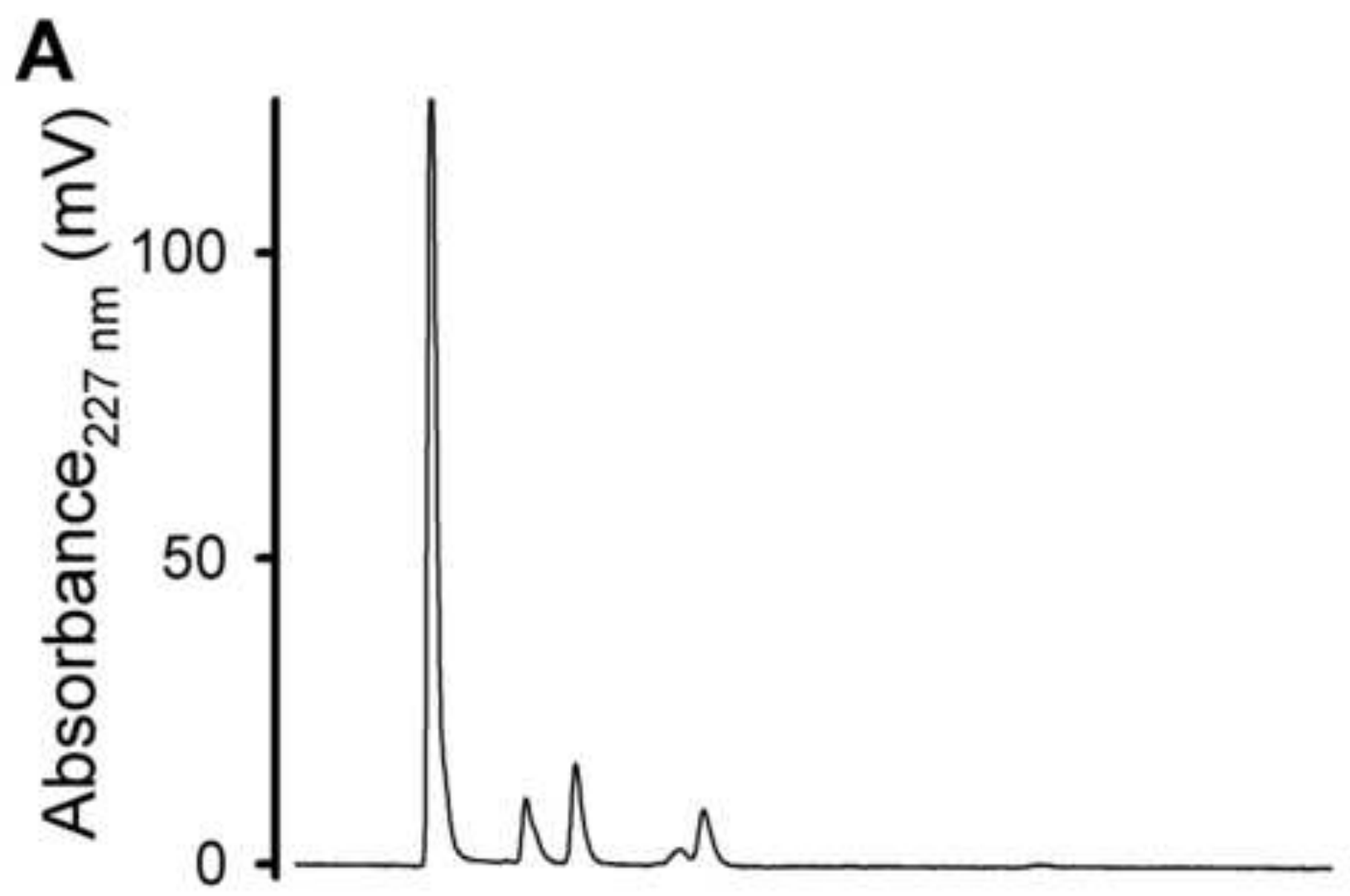

B

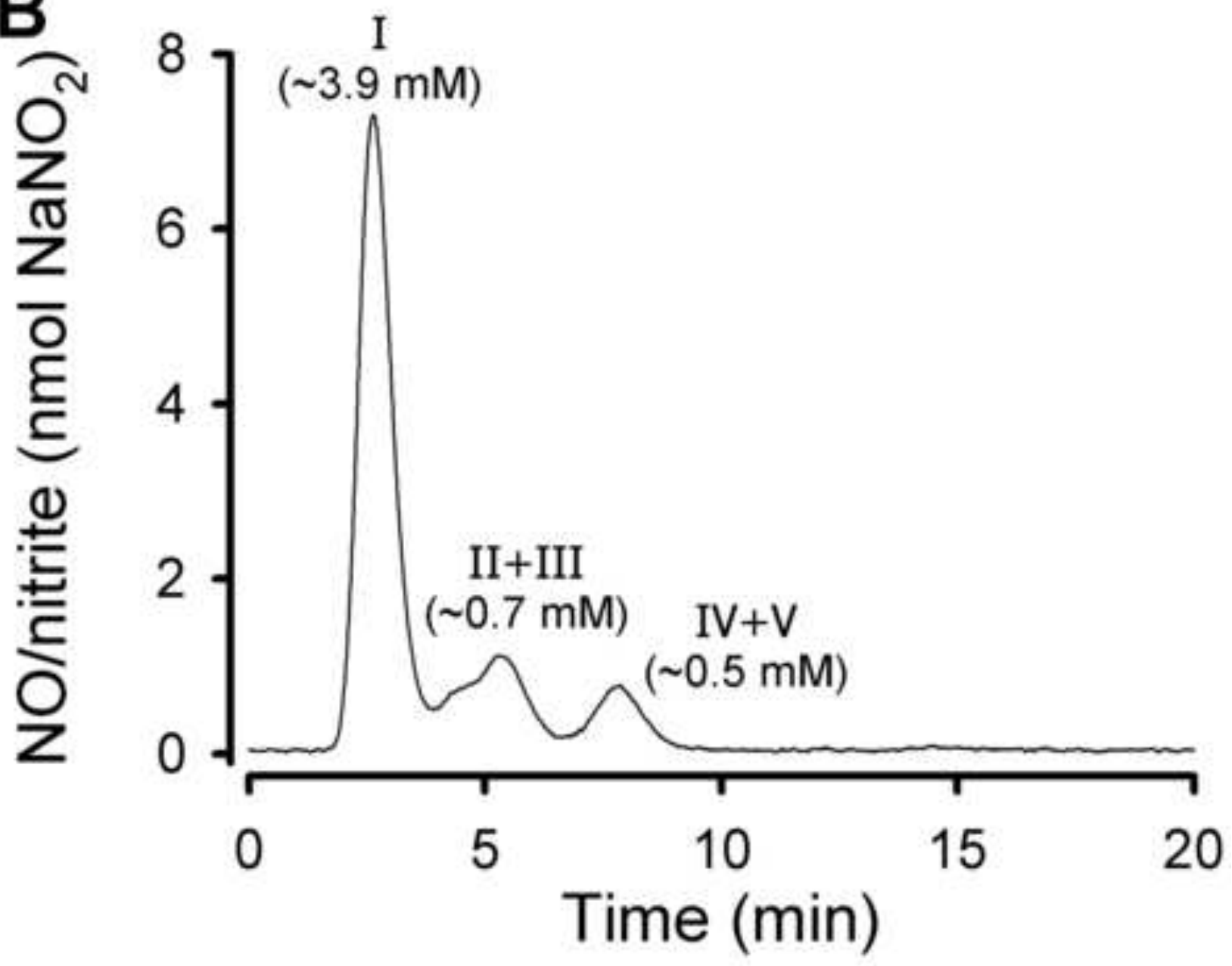

rage 52 of 58 


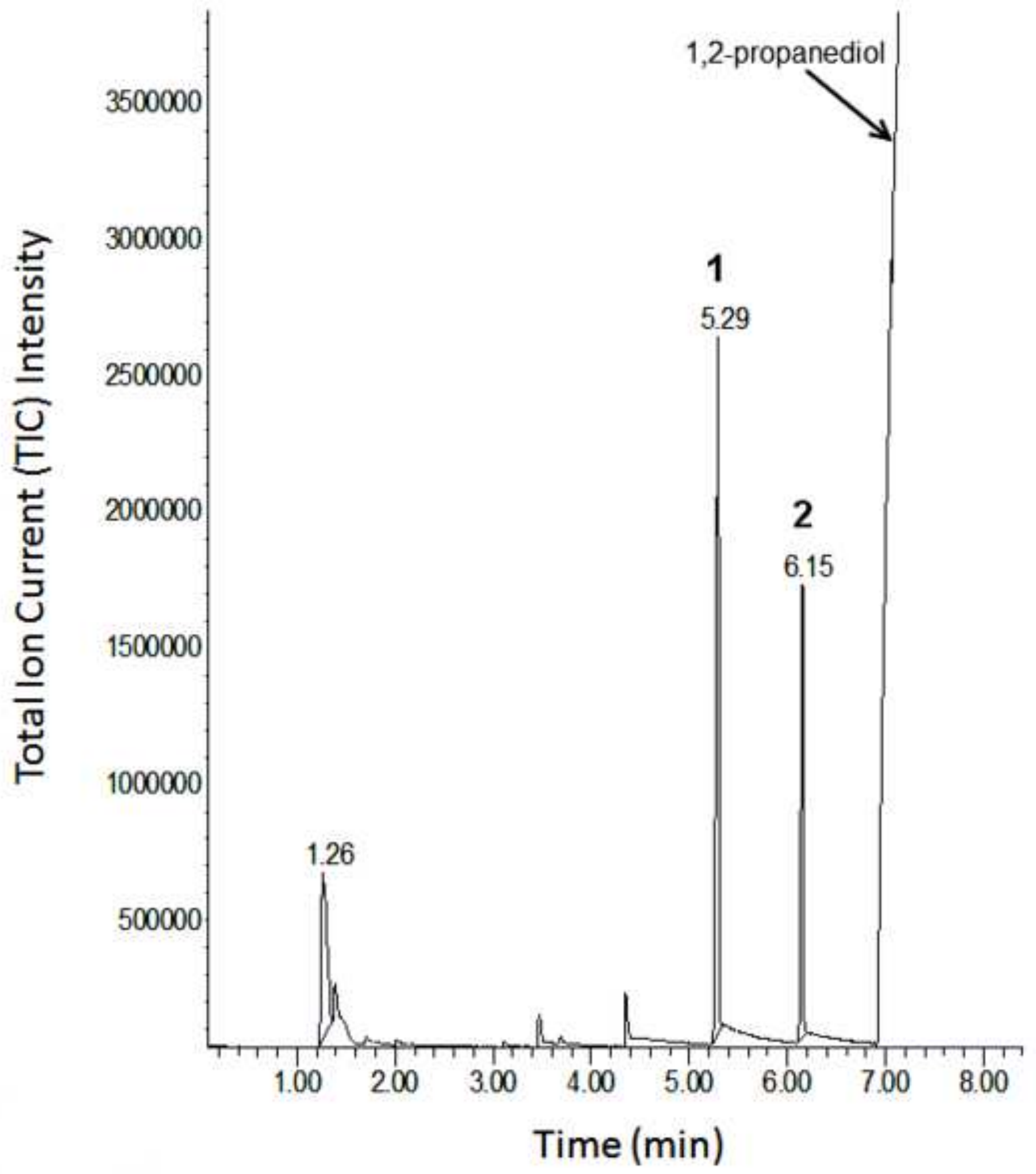

Page 53 of 58 


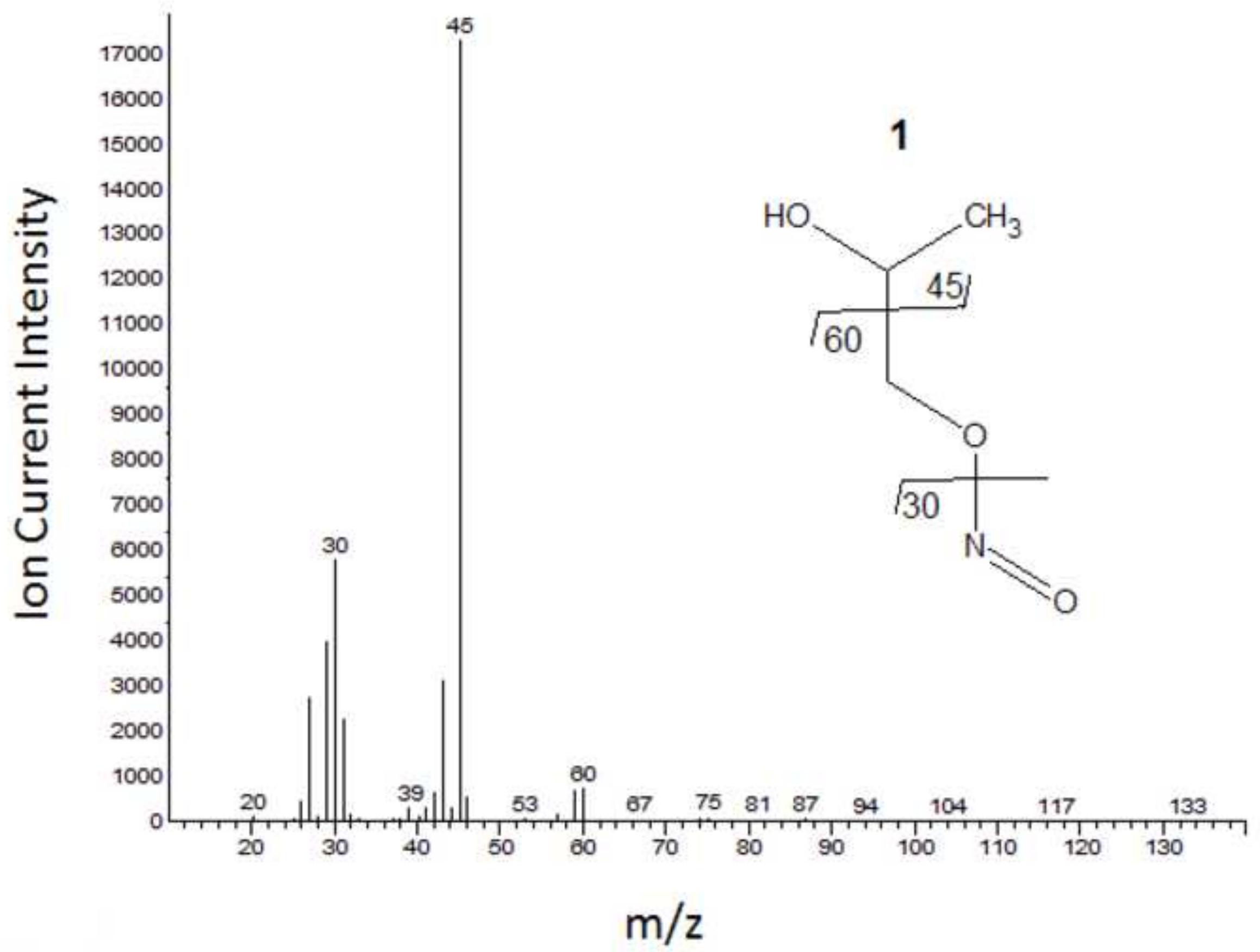

rage 54 or ๖ 


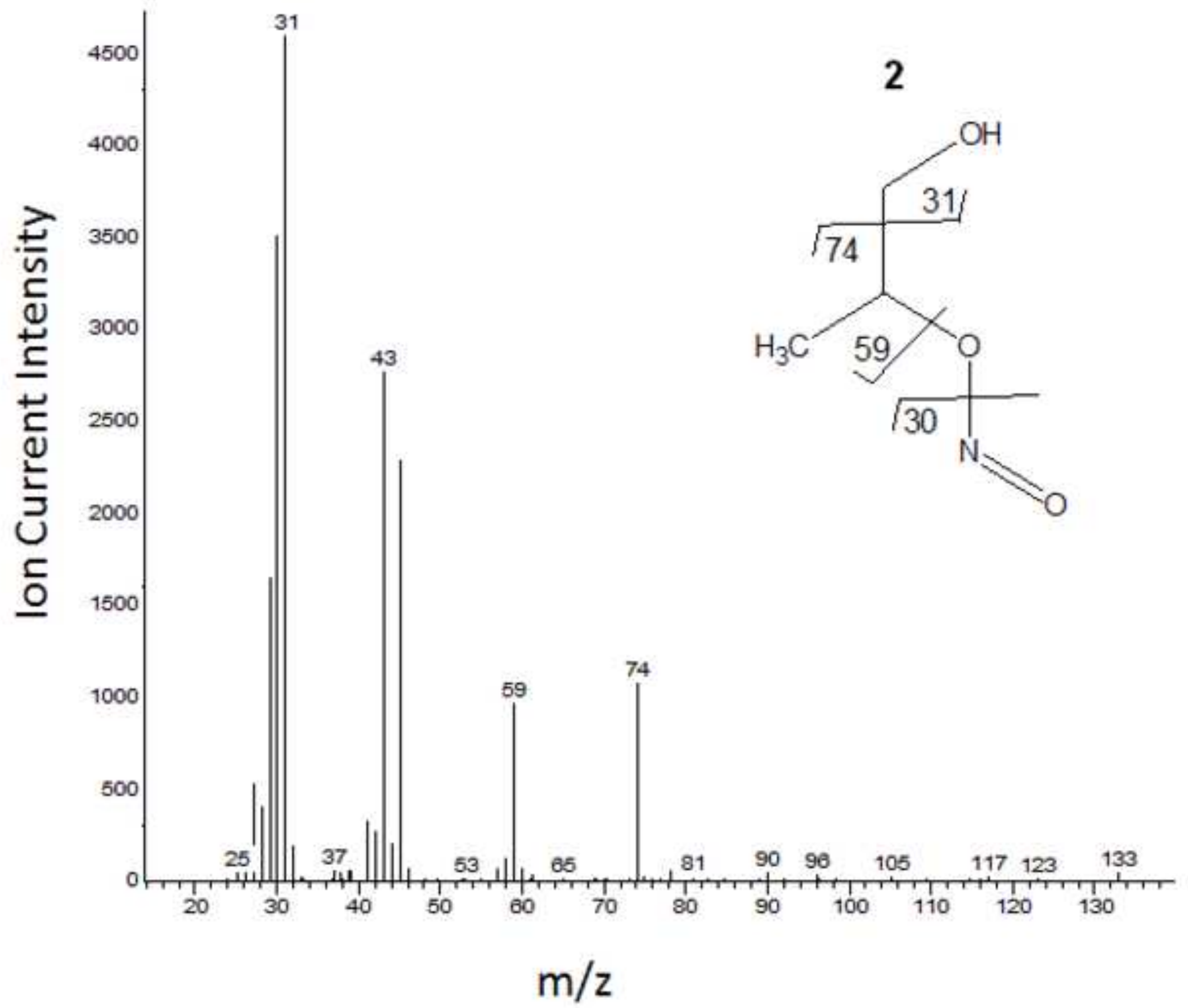

rage $\zeta$ o о 


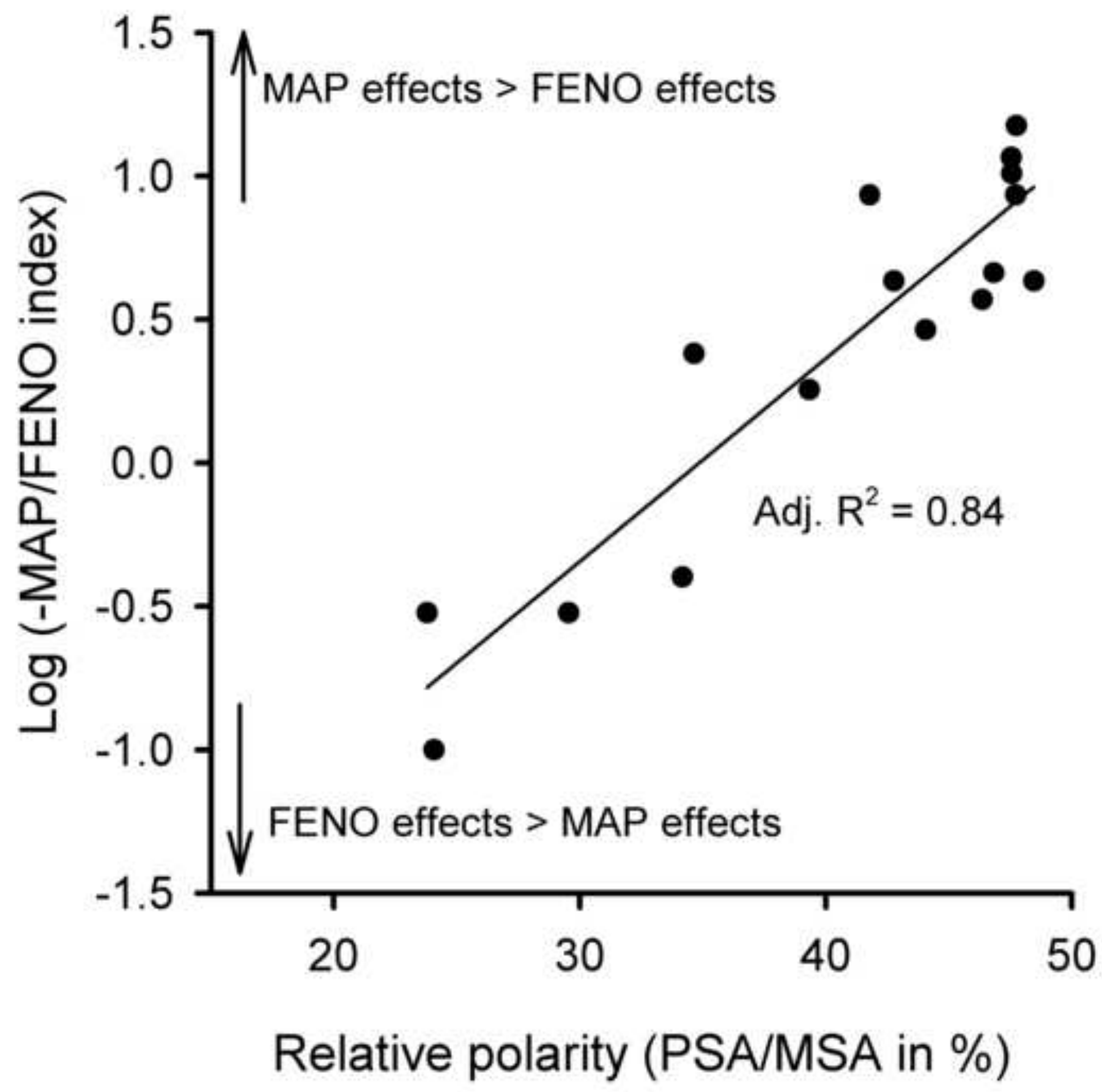




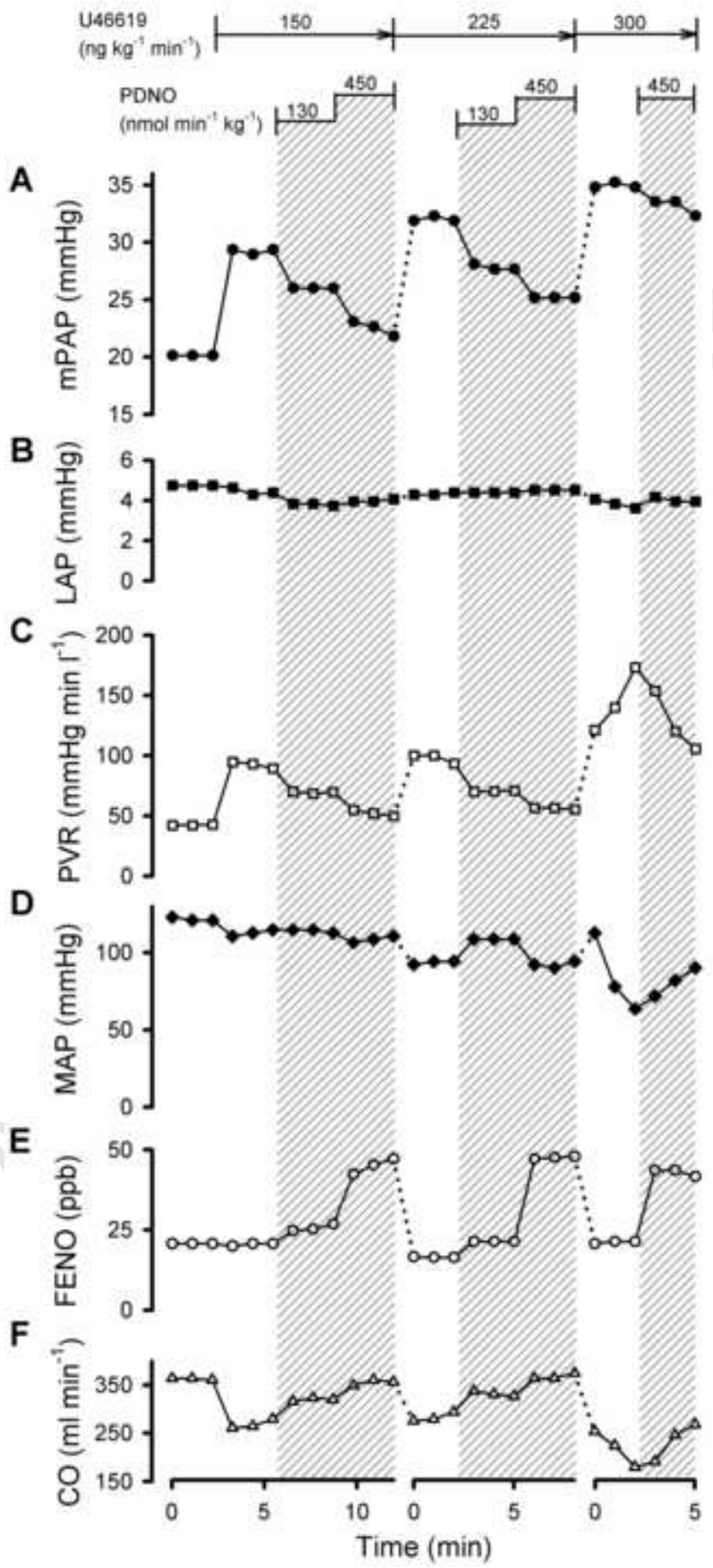


A

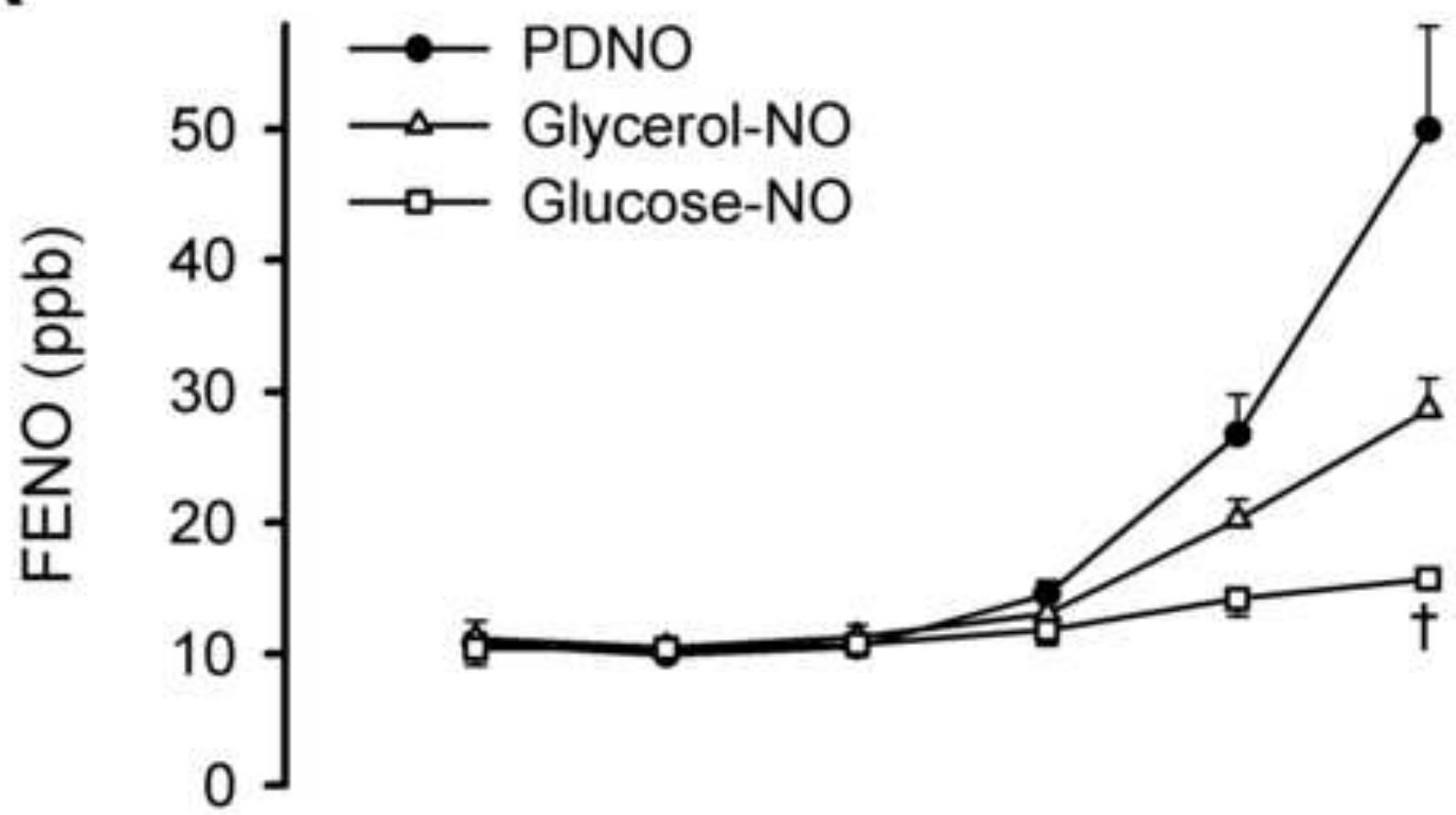

B

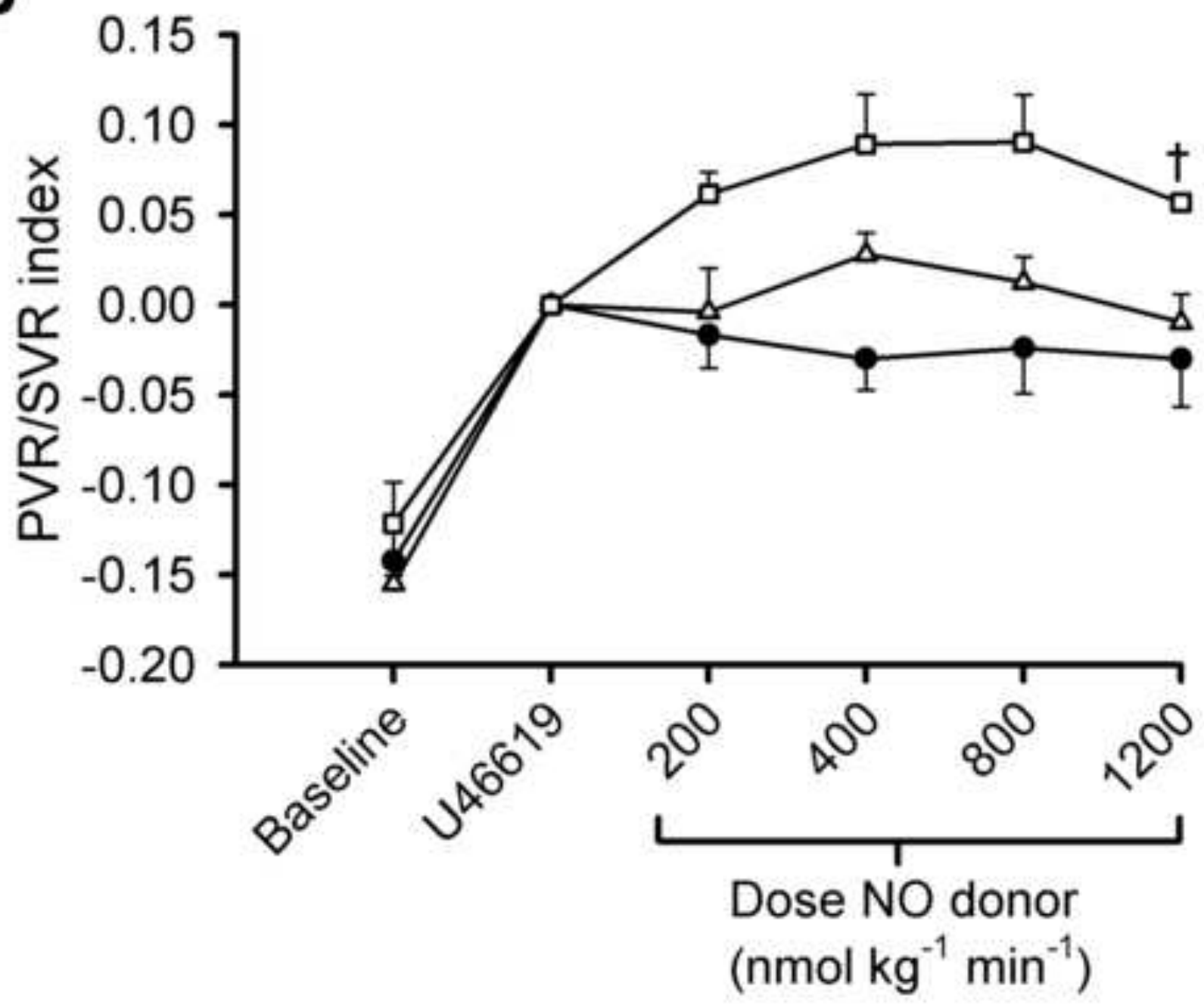

